\title{
Normalizing the Local Incidence Angle in Sentinel-1 Imagery to Improve Leaf Area Index, Vegetation Height, and Crop Coefficient Estimations
}

\author{
Gregoriy Kaplan ${ }^{1}\left(\mathbb{D}\right.$, Lior Fine ${ }^{1,2}$, Victor Lukyanov ${ }^{1}$, V. S. Manivasagam ${ }^{1,3} \mathbb{D}^{\text {, Josef Tanny }}$, $^{1,4}$ \\ and Offer Rozenstein $1, *$
}

check for updates

Citation: Kaplan, G.; Fine, L.; Lukyanov, V.; Manivasagam, V.S.; Tanny, J.; Rozenstein, O. Normalizing the Local Incidence Angle in Sentinel-1 Imagery to Improve Leaf Area Index, Vegetation Height, and Crop Coefficient Estimations. Land 2021, 10, 680. https://doi.org/ 10.3390/land 10070680

Academic Editors: Carmine Serio, Guido Masiello and Sara Venafra

Received: 29 May 2021

Accepted: 22 June 2021

Published: 28 June 2021

Publisher's Note: MDPI stays neutra with regard to jurisdictional claims in published maps and institutional affiliations.

Copyright: (c) 2021 by the authors. Licensee MDPI, Basel, Switzerland. This article is an open access article distributed under the terms and conditions of the Creative Commons Attribution (CC BY) license (https:/ / creativecommons.org/licenses/by/ $4.0 /)$.
1 Institute of Soil, Water and Environmental Sciences, Agricultural Research Organization-Volcani Institute, HaMaccabim Road 68, P.O. Box 15159, Rishon LeZion 7528809, Israel; grigorii@volcani.agri.gov.il (G.K.); liorf@volcani.agri.gov.il (L.F.); viclukyanov@gmail.com (V.L.); vs_manivasagam@cb.amrita.edu (V.S.M.); tanai@volcani.agri.gov.il (J.T.)

2 Department of Soil and Water Sciences, Faculty of Agriculture, Food and Environment, The Hebrew University of Jerusalem, P.O. Box 12, Rehovot 76100, Israel

3 Amrita School of Agricultural Sciences, Amrita Vishwa Vidyapeetham, J. P. Nagar, Arasampalayam, Myleripalayam, Coimbatore 642 109, Tamil Nadu, India

4 HIT-Holon Institute of Technology, Holon 58102, Israel

* Correspondence: offerr@volcani.agri.gov.il

Abstract: Public domain synthetic-aperture radar (SAR) imagery, particularly from Sentinel-1, has widened the scope of day and night vegetation monitoring, even when cloud cover limits optical Earth observation. Yet, it is challenging to combine SAR images acquired at different incidence angles and from ascending and descending orbits because of the backscatter dependence on the incidence angle. This study demonstrates two transformations that facilitate collective use of Sentinel-1 imagery, regardless of the acquisition geometry, for agricultural monitoring of several crops in Israel (wheat, processing tomatoes, and cotton). First, the radar backscattering coefficient $\left(\sigma^{0}\right)$ was multiplied by the local incidence angle $(\theta)$ of every pixel. This transformation improved the empirical prediction of the crop coefficient $\left(\mathrm{K}_{\mathrm{c}}\right)$, leaf area index $(\mathrm{LAI})$, and crop height in all three crops. The second method, which is based on the radar brightness coefficient $\left(\beta^{0}\right)$, proved useful for estimating $\mathrm{K}_{\mathrm{c}}$, LAI, and crop height in processing tomatoes and cotton. Following the suggested transformations, $\mathrm{R}^{2}$ increased by 0.0172 to 0.668 , and RMSE improved by 5 to $52 \%$. Additionally, the models based on the suggested transformations were found to be superior to the models based on the dual-polarization radar vegetation index (RVI). Consequently, vegetation monitoring using SAR imagery acquired at different viewing geometries became more effective.

Keywords: Sentinel-1; SAR; RVI; incidence angle; crop coefficient; leaf area index

\section{Introduction}

Spaceborne monitoring of agricultural landscapes is predominantly performed using optical sensors and synthetic-aperture radar (SAR). The use of passive optical remote sensing in the visual, near-infrared, shortwave infrared, and thermal spectral regions for the estimation of agricultural variables is well established [1-10]. However, optical sensors are limited by cloud cover. To overcome this problem, previous studies have suggested combining observations acquired at different times by several optical sensors [11-15], but even this approach does not always produce enough cloud-free observations to monitor cloudy regions effectively. Moreover, leaf area index (LAI) estimation from optical imagery suffers from a saturation effect when the LAI is greater than 3 [16-20]. Overcoming this limitation is desirable since LAI is commonly used as a measure of crop growth, nitrogen, and fertilization status estimation [21]. The LAI is also a good proxy for vegetation vigor [22,23], and a good yield predictor [24-27]. 
This study proposes complementing optical remote sensing with SAR to overcome these obstacles in monitoring vegetation properties and to facilitate better agricultural practices [28]. SAR penetration of the canopy can mitigate saturation in LAI estimation [29-31]. Moreover, since SAR can penetrate clouds, it produces high-quality imagery even in adverse weather conditions [32]. In addition to the LAI, remote sensing can be used to estimate other variables such as the crop coefficient $\left(\mathrm{K}_{\mathrm{c}}\right)$ and height. $\mathrm{K}_{\mathrm{c}}$-based estimation of crop water consumption is one of the most commonly used irrigation management methods [33,34]. Crop height is a good predictor of the aboveground biomass [35] and is commonly used by growers as a proxy for crop development. Therefore, deriving reliable SAR-based LAI, $\mathrm{K}_{\mathrm{c}}$, and height estimation models can facilitate better agricultural monitoring, especially in cloudy regions.

Several studies have employed spaceborne SAR for agricultural purposes [36-40] and demonstrated that quad-polarization SAR (e.g., RADARSAT-2, TerraSAR-X/TanDEM-X) could be used for crop monitoring. However, quad-polarization SAR images currently come at a high cost that limits their use in routine monitoring of crops and in research. Since 2014, the Sentinel-1 mission, consisting of two polar-orbiting satellites, provides a dual-polarization alternative at no cost to the user. These satellites have a revisit time of six days at $30^{\circ}$ latitude at the same viewing geometry and a $10 \times 10 \mathrm{~m}$ pixel size, thus having significant potential for agricultural applications.

One of the most critical challenges in creating time series of SAR imagery is the dependence of radar backscatter on the incidence angle [41]. The incidence angle is defined by the incident radar beam and the vertical (normal) to the surface. More specifically, the local incidence angle $(\theta)$ takes into account the local relief. The backscatter is weaker in images acquired at shallow incidence angles compared to images acquired at steeper incidence angles; therefore, the same object has different and uncomparable backscatter values in images acquired with different incidence angles. Given the dependence of the backscatter's intensity on the incidence angle, previous studies have underlined the need to correct this effect $[42,43]$. Until now, many studies using C-band SAR imagery from Sentinel-1, RADARSAT-2, and RISAT-1 for agricultural monitoring only used a subset of the available imagery acquired from either ascending or descending orbits with a limited range of incidence angles. Accordingly, these studies discarded imagery acquired at incidence angles that fell outside certain margins (Table 1). This practice might exclude more than half of the available images from the time series. Moreover, empirical models developed based on these limited datasets are likely applicable only for the same range of incidence angles. Therefore, the practice of excluding images from the time series reduces the applicability of SAR-based models.

Table 1. Summary of the incidence angle range considered in past studies.

\begin{tabular}{lllll}
\hline Study & Incidence Angle ( ${ }^{\circ}$ ) & Satellite & Crop & Application \\
\hline Van Tricht et al. (2018) [44] & $32-42$ & Sentinel-1 & Many crops & Crop classification \\
\hline Inoue et al. (2014) [45] & $25-35$ & RADARSAT-2 & Paddy rice & $\begin{array}{l}\text { Various biophysical } \\
\text { variables }\end{array}$ \\
\hline Veloso et al. (2017) [46] & $38-41$ & Sentinel-1 & $\begin{array}{l}\text { Wheat, rapeseed, maize, } \\
\text { soybean, sunflower }\end{array}$ & Temporal behavior \\
\hline Bousbih et al. (2017) [47] & $39-40$ & Sentinel-1 & Cereals & Crop height and LAI \\
\hline Nasirzadehdizaji et al. (2019) [48] & $39-40$ & Sentinel-1 & Maize, sunflower, wheat & $\begin{array}{l}\text { Crop height and } \\
\text { canopy coverage }\end{array}$ \\
\hline Navarro et al. (2016) [49] & $38.87-39.26$ & Sentinel-1 & $\begin{array}{l}\text { Maize, soybean, } \\
\text { bean, pasture }\end{array}$ & $\begin{array}{l}\text { Crop water } \\
\text { requirements }\end{array}$ \\
\hline Inglada et al. (2016) [50] & $38.89-39.05$ & Sentinel-1 & $\begin{array}{l}\text { Wheat, rapeseed, barley, } \\
\text { corn, sunflower }\end{array}$ & Crop classification \\
\hline Hosseini et al. (2018) [51] & $20.63-28.16$ & RADARSAT-2 & Corn & Biomass \\
\hline
\end{tabular}


Table 1. Cont.

\begin{tabular}{|c|c|c|c|c|}
\hline Study & Incidence Angle $\left(^{\circ}\right)$ & Satellite & Crop & Application \\
\hline Phan et al. (2021) [52] & $42-44$ & Sentinel-1 & Rice & $\begin{array}{l}\text { Various biophysical } \\
\text { variables }\end{array}$ \\
\hline Molijn et al. (2019) [53] & $36.0-36.6$ & Sentinel-1 & Sugarcane & Productivity mapping \\
\hline Demarez et al. (2019) [54] & 30 & Sentinel-1 & Maize & Crop mapping \\
\hline Srivastava et al. (2019) [55] & 31 & RISAT-1 & Wheat & Crop height \\
\hline Srivastava et al. (2018) [56] & 32 & RISAT-1 & Paddy & LAI \\
\hline Benabdelouahab et al. (2018) [57] & 23.3 & ERS-1 & Wheat & $\begin{array}{l}\text { Irrigation supply } \\
\text { detection }\end{array}$ \\
\hline Han et al. (2019) [58] & 42.5 & Sentinel-1 & Wheat & Crop water content \\
\hline Yadav et al. (2019) [59] & 40 & Sentinel-1 & Wheat & LAI \\
\hline Chauhan et al. (2018) [60] & 38 & RISAT-1 & Wheat & $\begin{array}{l}\text { Various biophysical } \\
\text { variables }\end{array}$ \\
\hline Harfenmeister et al. (2019) [61] & $\begin{array}{l}\text { Constant. } \\
\text { Undisclosed. }\end{array}$ & Sentinel-1 & Wheat, barley & $\begin{array}{l}\text { Various biophysical } \\
\text { variables }\end{array}$ \\
\hline Song and Wang (2019) [62] & $\begin{array}{l}\text { Constant. } \\
\text { Undisclosed. }\end{array}$ & Sentinel-1 & Wheat & $\begin{array}{l}\text { Crop classification and } \\
\text { phenology monitoring }\end{array}$ \\
\hline Nihar et al. (2019) [63] & $\begin{array}{l}\text { Constant. } \\
\text { Undisclosed. }\end{array}$ & Sentinel-1 & Cotton, maize & Crop classification \\
\hline Vreugdenhil et al. (2018) [64] & $\begin{array}{l}\text { Constant. } \\
\text { Undisclosed. }\end{array}$ & Sentinel-1 & $\begin{array}{l}\text { Corn, cereals, } \\
\text { oilseed rape }\end{array}$ & $\begin{array}{l}\text { Various biophysical } \\
\text { variables }\end{array}$ \\
\hline
\end{tabular}

Several different incidence angle normalization procedures were carried out in previous studies. For example, [44] normalized their selected subset of imagery (incidence angles between $32^{\circ}$ and $42^{\circ}$ ) to $37^{\circ}$ using a simplified correction method based on Lambert's law of optics. However, this method is insufficiently effective because it is relatively reliable only at the center of the image $[41,65]$. Two new effective methods for incidence angle normalization were proposed by [65], but environmental conditions limited the applicability of these methods, and they have been used mostly for ocean monitoring. Other methods for incidence angle normalization, such as simplified normalization [43], radiative transfer-based models, and statistical methods, can be applied only under specific ground conditions [66]. Therefore, despite past attempts to deal with the heterogeneity of the incidence angle in the SAR time series, the challenge of incidence angle normalization remains.

Therefore, the main goal of this study was to propose methods to reduce the backscatter dependence on the local incidence angle to permit the use of all available Sentinel-1 images in a single dataset without defining a range of allowed incidence angles and omitting images that extend beyond it. The second goal of this study was to use the proposed methods to accurately estimate vegetation properties (Kc, LAI, and crop height) based on incidence angle-normalized Sentinel- 1 imagery.

\section{Materials and Methods}

\subsection{Test Sites and Field Measurements}

The field measurements used in this study were carried out during two seasons of winter wheat, three seasons of processing tomatoes, and two seasons of cotton in different locations in Israel (Table 2, Figure 1). LAI was measured by a SunScan Canopy Analysis System-SS1 developed by Delta-T Company (Cambridge, United Kingdom) during two wheat seasons and two processing tomato seasons. The SunScan is an accurate, nondestructive LAI measurement system successfully employed in many previous studies [25,67]. Each LAI value is an average of at least 30 consecutive field measurements taken at $20-\mathrm{cm}$ intervals along a transect perpendicular to the row direction. Vegetation height was mea- 
sured at a precision of $1 \mathrm{~cm}$ using a tape measure and represented by an average of at least 30 plants per measurement date. LAI and vegetation height in wheat and processing tomatoes were measured throughout the growing seasons; therefore, they represent the full range of these variables. Cotton height was measured during the middle and late stages of one growing season. The backscattering coefficient $\left(\sigma^{0}\right)$ and the radar brightness coefficient $\left(\beta^{0}\right)$ were used in linear scale. Sentinel-1 backscatter values were averaged for a polygon that represented the eddy covariance measurement footprint calculated based on a two-dimensional footprint model [68]. All the empirical regression models in this study utilized the average values of either $\sigma^{0}$ or $\beta^{0}$, and the local incidence angle $(\theta)$ within the areas of interest and same-date field measurements. In cases of gaps in the time series, linearly interpolated values of field measurements from adjacent dates (crop height and LAI) were used. The number of SAR images used for the derivation of the various models was not uniform because each model was based on the period for which field measurements were available, resulting in different numbers of corresponding satellite images. For example, LAI could not be measured using the SunScan system when the plants were very small, while vegetation height was easily measured at any time using a ruler. Accordingly, the LAI models were based on shorter time spans and fewer images than were plant height models. In-field paths and their surrounding area were masked out from analysis polygons of the processing tomato experiments which took place in 2019 to remove bare soil areas and avoid border effects. These excluded areas consisted of approximately 20\% of the overall areas of interest. Therefore, the Gadash 2019 area of interest consisted of four vegetated regions separated by paths, and the Gadot 2019 area of interest consisted of two regions.

Table 2. Summary of seven field experiments conducted at six locations in Israel.

\begin{tabular}{|c|c|c|c|c|c|c|c|}
\hline $\begin{array}{l}\text { Experiment } \\
\text { Area }\end{array}$ & Crop & Period * & $\begin{array}{l}\text { \# Crop } \\
\text { Height Mea- } \\
\text { surements }\end{array}$ & $\begin{array}{l}\text { \# LAI Mea- } \\
\text { surements }\end{array}$ & $\begin{array}{l}\text { Area Size (\# } \\
\text { Sentinel-1 } \\
\text { Pixels) }\end{array}$ & $\begin{array}{l}\text { Nearest Mete- } \\
\text { orological } \\
\text { Station } \mathrm{ET}_{0} \\
\text { Data }\end{array}$ & $\begin{array}{l}\text { Distance and } \\
\text { Bearing to the } \\
\text { Meteorological } \\
\text { Station }\end{array}$ \\
\hline Saad & Wheat & $\begin{array}{l}\text { 1-Jan-2018 } \\
\text { 9-Apr-2018 }\end{array}$ & 8 & 6 & 260 & Dorot & $9.5 \mathrm{~km} \mathrm{NE}$ \\
\hline Yavne & Wheat & $\begin{array}{l}\text { 18-Dec-2018 } \\
\text { 10-Apr-2019 }\end{array}$ & 7 & 7 & 550 & - & - \\
\hline Tel Nof & Cotton & $\begin{array}{l}\text { 6-Jun-2016 } \\
\text { 17-Sep-2016 }\end{array}$ & 7 & - & 1300 & Revadim & $5 \mathrm{~km} \mathrm{~S}$ \\
\hline Negba & Cotton & $\begin{array}{l}\text { 25-Jul-2017 } \\
\text { 11-Sep-2017 }\end{array}$ & - & - & 460 & Negba & $2.5 \mathrm{~km} \mathrm{SW}$ \\
\hline Gadash & $\begin{array}{l}\text { Processing } \\
\text { tomatoes }\end{array}$ & $\begin{array}{l}\text { 9-May-2018 } \\
\text { 30-Jul-2018 }\end{array}$ & 8 & - & 250 & - & - \\
\hline Gadash & $\begin{array}{l}\text { Processing } \\
\text { tomatoes }\end{array}$ & $\begin{array}{l}\text { 3-May-2019 } \\
\text { 24-Jul-2019 }\end{array}$ & 7 & 6 & 500 & Gadash & $250 \mathrm{~m} \mathrm{SE}$ \\
\hline Gadot & $\begin{array}{l}\text { Processing } \\
\text { tomatoes }\end{array}$ & $\begin{array}{l}\text { 25-Apr-2019 } \\
\text { 14-Aug-2019 }\end{array}$ & 11 & 11 & 300 & Gadot & $1.5 \mathrm{~km} \mathrm{SW}$ \\
\hline
\end{tabular}

Note: * Period indicates the starting and ending dates.

\subsection{Agro-Meteorological Measurements}

Agro-meteorological measurements of the reference evapotranspiration $\left(\mathrm{ET}_{0}\right)$ and actual evapotranspiration $\left(\mathrm{ET}_{\mathrm{c}}\right)$ were performed to derive the crop coefficient $\left(\mathrm{K}_{\mathrm{c}}\right)$ as $\mathrm{K}_{\mathrm{c}}=\mathrm{ET}_{\mathrm{c}} / \mathrm{ET}_{0} . \mathrm{K}_{\mathrm{c}}$ is an important variable used to determine the irrigation dose [69]. Daily $\mathrm{ET}_{\mathrm{c}}$ was derived from water vapor flux measurements by eddy covariance systems $[6,70]$. The daily $\mathrm{ET}_{0}$ was calculated according to the Penman-Monteith method [33] based on meteorological measurements of air temperature, relative humidity, wind speed, and solar irradiance at the meteorological station closest to the field or at the flux tower itself (Table 2). Meteorological station data are publicly available at http:/ /www.meteo.co.il/ (accessed on 24 June 2021) and http:/ / www.mop-zafon.net/ (accessed on 24 June 2021). The $\mathrm{K}_{\mathrm{c}}$ data used for developing the processing tomato models were smoothed in Python 
with the SciPy library using the cubic and the second-order splines. Smoothing spline is a non-parametric regression technique, which was previously used in various remote sensing applications $[15,71-73]$. $\mathrm{ET}_{\mathrm{c}}$ was measured throughout the growing seasons of wheat and processing tomatoes and from the middle of the cotton growing seasons. $\mathrm{ET}_{\mathrm{c}}$ data collected during the Gadash processing tomato experiment in 2018 and the Yavne 2019 wheat experiment were not used for the $K_{c}$ model development because more than half the data were lost due to technical difficulties that emerged during the experiments.

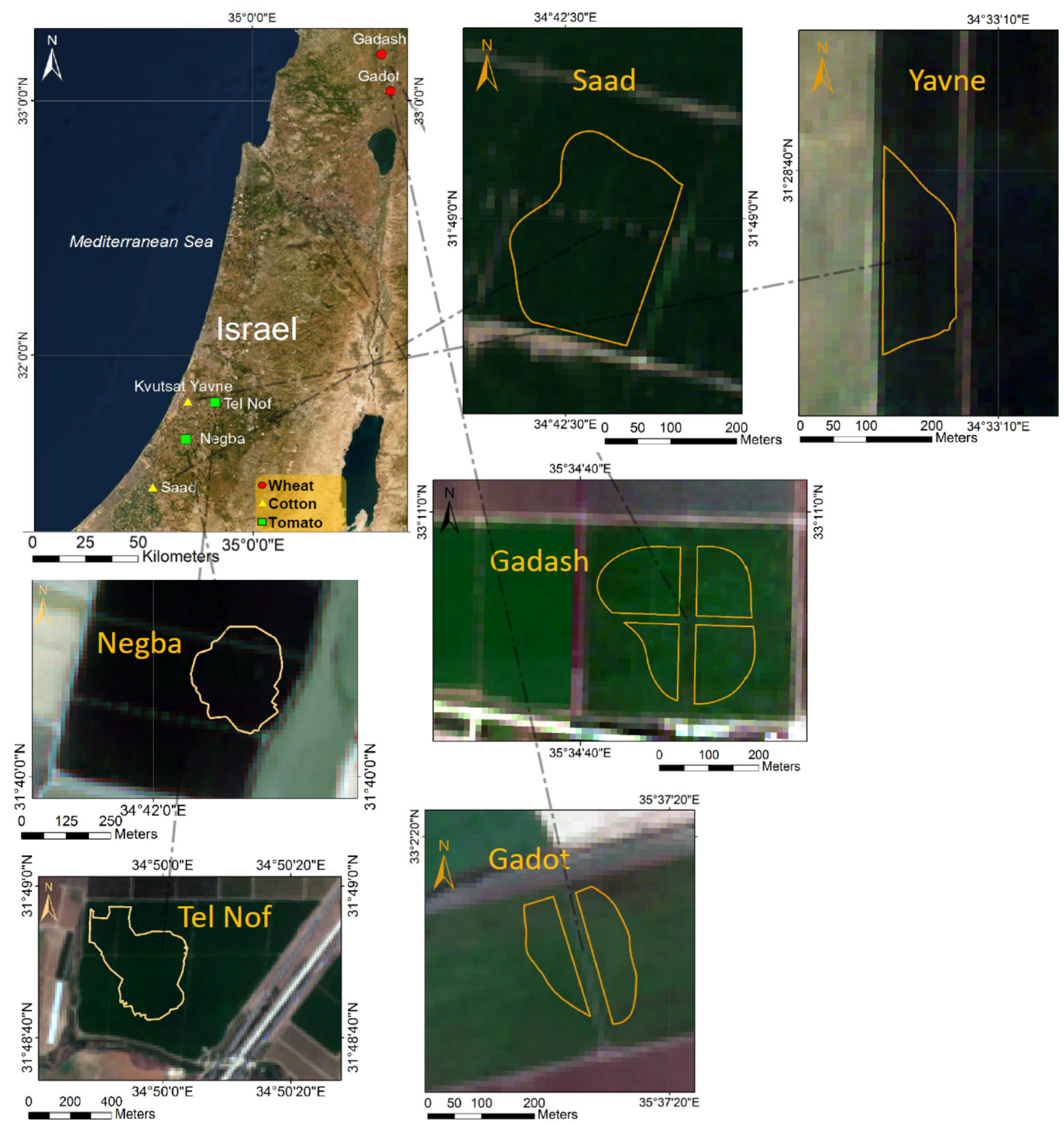

Figure 1. Locations of analysis polygons in the experiments conducted in Israel in 2016-2019.

\subsection{Satellite Imagery}

Sentinel-1 is part of the European Copernicus program for Earth observation. The payload of the two Sentinel-1 satellites includes a dual-polarization (VV and VH) C-band SAR instrument that is an active phased array antenna working at $5.405 \mathrm{GHz}$ frequency (corresponding wavelength $5.55 \mathrm{~cm}$ ). The resolution of the Level-1 Ground Range Detected (GRD) Interferometric Wide (IW) mode that was used in this study is $20 \times 22 \mathrm{~m}$, with a 
pixel size of $10 \times 10 \mathrm{~m}$, swath width of $250 \mathrm{~km}$, and a revisit time of six days for images with the same geometry. Sentinel-1A and Sentinel-1B were launched on 3 April 2014 and on 25 April 2016, respectively. The Sentinel-1 incidence angle in the IW mode ranges approximately between $29^{\circ}$ and $46^{\circ}$. Figure 2 shows the graphical representation of the local incidence angle. In this study, some sites were close to the edge of the images, resulting in an incidence angle range from $30.8^{\circ}$ to $45.8^{\circ}$, and in local incidence angle values from $30.3^{\circ}$ to $47.7^{\circ}$ (Figure 3 ). Therefore, this study was based on a wide range of incidence angles. The areas within SAR imagery used in the present study are not affected by adverse geometrical effects, such as radar shadow, foreshortening, and layover. The SAR imagery used in this study was downloaded from the ESA Copernicus site (https:/ / scihub.copernicus.eu/dhus/\#/home, accessed on 23 June 2021). Overall, 38 SAR images were used to derive models for wheat (Table S1), 19 for cotton (Table S2), and 94 for processing tomatoes (Table S3), Figure 3).

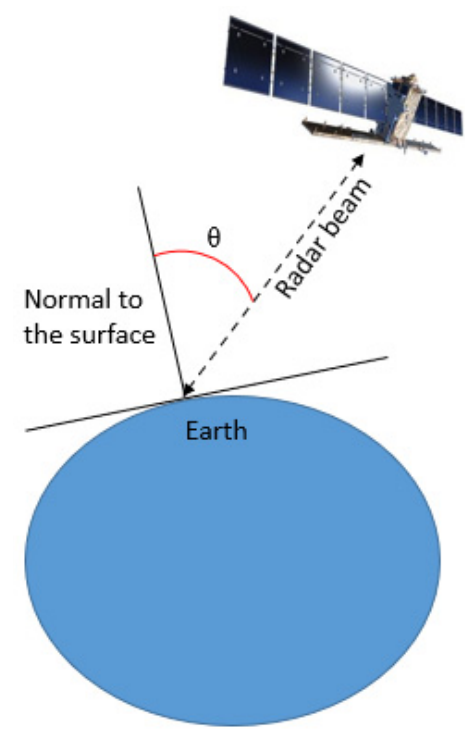

Figure 2. Local incidence angle $(\theta)$. The local incidence angle $(\theta)$ is defined as the angle between the incidence radar beam and a line that is normal to the surface, considering local relief, typically derived from a DEM.

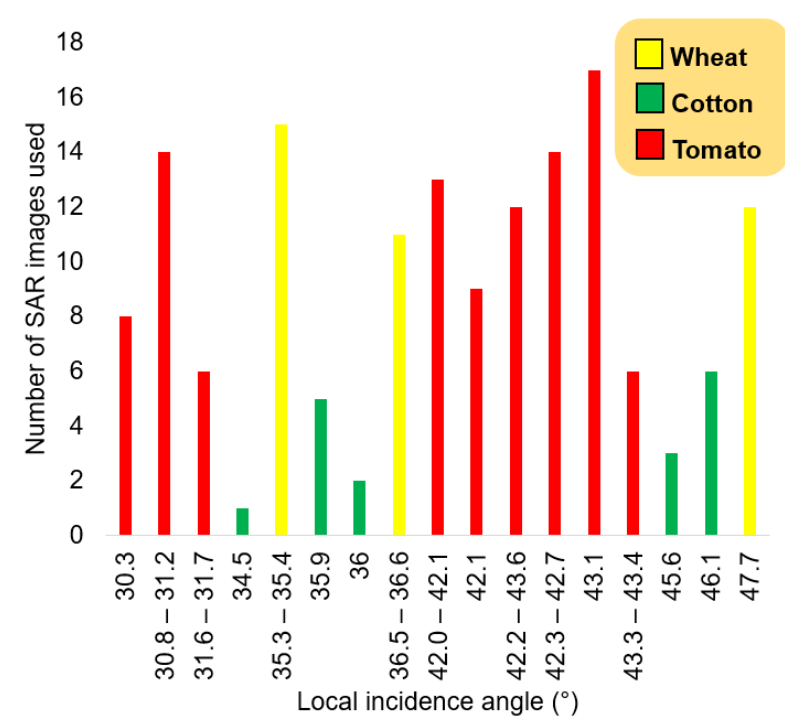

Figure 3. The number of SAR images acquired at different local incidence angles used in the modeling of different crops. 


\subsection{Image Processing}

All images were pre-processed in the Sentinel Application Platform (SNAP versions 6.0 and 7.0, European Space Agency). The sequential pre-processing of the Sentinel-1 imagery was as follows: subsetting a region around the target area, applying the latest orbit file to correct for the satellite path, thermal noise removal, calibration to $\beta^{0}$ and $\sigma^{0}$ in a natural scale, range Doppler terrain correction using the Shuttle Radar Topography Mission (SRTM, [74]) digital elevation model (DEM) with $30 \mathrm{~m}$ resolution. These pre-processing steps were performed in the same sequence as in Song et al. [62], with the addition of the thermal noise removal step that was also performed by Van Tricht et al. [44]. The speckle filtering operation was avoided; therefore, the spatial resolution was retained [75-77].

\subsection{Dual-Polarized RVI Algorithm}

One of the conventional approaches for agricultural monitoring from quad-polarization SAR data is the calculation of the radar vegetation index (RVI) [40]. An adaptation for Sentinel-1 data assumes that $\sigma_{\mathrm{VV}}^{0} \approx \sigma_{\mathrm{HH}}^{0}$ [78-80], such that

$$
\mathrm{RVI}=\frac{4 * \sigma_{\mathrm{VH}}^{0}}{\sigma_{\mathrm{VH}}^{0}+\sigma_{\mathrm{VV}}^{0}}
$$

The radar backscatter coefficient, $\sigma^{0}$, also known as the radar cross-section (RCS) per unit area, is the conventional measure of the intensity of the signal reflected by the surface. It is a normalized dimensionless number that varies significantly with the incidence angle, wavelength, and polarization, as well as with properties of the scattering surface itself [81].

Each RVI model in the present study was based only on one dataset with the maximum number of images acquired at an ascending orbit with the same incidence angle. These are considered to be the most favorable conditions for determining the RVI without incidence angle normalization. An RVI-based $\mathrm{K}_{\mathrm{c}}$ model for cotton was not produced because of the lack of imagery acquired at the same incidence angle over the specific fields where the agro-meteorological measurements were performed. The models based on the suggested methods for local incidence angle normalization methods described in Sections 2.6 and 2.7 were compared to the models based on the RVI.

\section{6. $\sigma^{0}$-Based Local Incidence Angle Normalization}

The radar backscatter intensity depends on the incidence angle, with $\sigma^{0}$ decreasing proportionally to the incidence angle increase in the intermediate range of incidence angles typical for Sentinel-1 and the majority of spaceborne SAR missions [43,82-84]. Based on this understanding, $\sigma^{0}$ was normalized by multiplying it with the local incidence angle $(\theta)$ in the decimal degree scale:

$$
\sigma_{\text {Norm }}^{0}=\sigma^{0} * \theta
$$

The normalization of $\sigma^{0}$ is achieved by multiplying lower $\sigma^{0}$ values obtained under shallower local incidence angles by higher $\theta$ values than the higher $\sigma^{0}$ values acquired under steeper local incidence angles. In this study, different $\mathrm{VV}$ and $\mathrm{VH}$ polarization combinations of normalized $\sigma^{0}$ values were used to model $K_{c}$, LAI, and crop height. The models described below (Equations (3)-(5)) were produced using polarization combinations that showed the best $R^{2}$ and RMSE values. The following polarization combination was used to model $\mathrm{K}_{\mathrm{c}}$ and LAI in wheat, and LAI in processing tomatoes:

$$
\mathrm{V}=\sigma_{\mathrm{Norm}, \mathrm{VH}}^{0}+\sigma_{\mathrm{Norm}, \mathrm{VV}}^{0}
$$

where, and afterward, $\mathrm{V}$ is a vegetation variable being estimated.

The following polarization combination was used to model wheat and cotton height:

$$
\mathrm{V}=\sigma_{\mathrm{Norm}, \mathrm{VH}}^{0}-\sigma_{\mathrm{Norm}, \mathrm{VV}}^{0}
$$


Processing tomato and cotton $\mathrm{K}_{\mathrm{c}}$ estimation models were based on

$$
\mathrm{V}=\sigma_{\mathrm{Norm}, \mathrm{VV}}^{0}
$$

The descending winter wheat imagery showed a very low correlation with wheat variables and, therefore, was not used for the development of wheat models.

\section{7. $\beta^{0}$-Based Local Incidence Angle Normalization Method for Tomato and Cotton Height, LAI, and $K_{c}$ Estimation}

A radar beam transmitted at a shallow angle travels longer distances through the vegetation canopy than a beam transmitted under a steep angle; thus, the attenuation of the former is typically higher than that of the latter. Apart from the beam two-way travel distance through the vegetation, the radar backscatter is affected by soil roughness, dielectric properties, and a combination of different types of scatterers that exist in each pixel $[85,86]$. The wheat fields in this study are flat, and the vegetation growth is uniform. Hence, scattering from the soil surface is mostly specular in the early part of the season, and the volume scattering component increases as the vegetation develops $[87,88]$. Unlike the wheat fields, the structure of processing tomatoes and cotton fields is more complex, with mounds and furrows. The distance between planted mound centers in all three processing tomato fields is two meters, and it is one meter in cotton. The difference between the elevation of the mounds is up to $15 \mathrm{~cm}$ in processing tomatoes and $12 \mathrm{~cm}$ in cotton. Consequently, the standard deviation of the surface height is up to $7.5 \mathrm{~cm}$ and 6 $\mathrm{cm}$ in processing tomatoes and cotton, respectively. According to the Peake and Oliver roughness criterion [89], the surface is considered rough if

$$
\mathrm{h}_{\mathrm{rms}}>\frac{\lambda}{4 * \cos \delta}
$$

where $h_{\text {rms }}$ is the standard deviation of the surface height variation; $\lambda$ is the wavelength; and $\delta$ is the incidence angle. The incidence angle is slightly different from the local incident angle for slopeless surfaces, but this difference does not affect the calculation of the roughness criterion. Accordingly, in C-band SAR with an incidence angle range of $30^{\circ}-45^{\circ}$, the roughness threshold is $\mathrm{h}_{\mathrm{rms}}>1.5 \mathrm{~cm}$ for an incidence angle of $30^{\circ}$, and $\mathrm{h}_{\mathrm{rms}}>1.8 \mathrm{~cm}$ for an incidence angle of $45^{\circ}$. Therefore, the processing tomato and cotton fields are rough, decreasing backscatter dependence on the incidence angles [85], and modifying the rate of backscatter change as the incidence angle increases [90]. Unlike the smooth wheat fields, every pixel in processing tomato and cotton fields contains multiple types of scattering: specular (plant-free furrows), double bounce (corners between furrows and mounds), and volume scattering in the canopy. Moreover, at some incidence angles, Bragg scattering caused by the row frequency might occur $[91,92]$.

Owing to the complex surface structure in cotton and processing tomato fields, another transformation method specific to these fields was derived empirically in addition to the $\sigma^{0}$ normalization method. This new method is based on the polynomial regression between plant variables multiplied by the newly derived attenuation coefficient $\sin \left(\operatorname{Radians}(90-\theta)^{3}\right)$ and radar brightness $\left(\beta^{0}\right)$ :

$$
\mathrm{V} * \sin \left(\operatorname{Radians}(90-\theta)^{3}\right)=\mathrm{A} *\left(\beta^{0}\right)^{2}+\mathrm{B} *\left(\beta^{0}\right)+\mathrm{C}
$$

where $\mathrm{V}$ is the plant variable (such as height, $\mathrm{LAI}$, or $\mathrm{K}_{\mathrm{c}}$ ); $\theta$ is the local incidence angle in degrees; A, B, and C are the specific model coefficients; and $\beta^{0}$ is the radar brightness coefficient [41] at either VV (processing tomatoes) or the sum of VV and VH polarizations (cotton). $\beta^{0}$ is a dimensionless coefficient that corresponds to the reflectivity per unit area in the slant range. $\beta^{0}$ is used because the radiometric correction of $\sigma^{0}$ is based on a sea-level ellipsoid $[41,93]$ and, therefore, less suitable for monitoring of rough surfaces and areas with a rugged topography [94]. Previous studies found $\beta^{0}$ to be the best unencumbered estimate 
SAR measurement $[41,95,96]$. Using radar brightness is an established practice for research in space $[97,98]$ and common practice in the analysis of RADARSAT- 1 imagery $[85,99]$, but not of Sentinel-1 data.

The attenuation coefficient $\sin \left(\operatorname{Radians}(90-\theta)^{3}\right)$ is used to account for the dependence of beam attenuation on the local incidence angle. The SAR beam interaction with objects on the ground can be described as a triangle in which the radar beam is the hypotenuse, and the local incidence angle $\theta$ is the angle between the hypotenuse and vertical cathetus normal to the surface (Figure 2). $\beta^{0}$ values are reconstructed to a normalized value by applying a sine function to a cubed value of the $(90-\theta)$ value in radians. The attenuation coefficient is linearly and inversely proportional to the local incidence angle, as shown in Figure 4. Therefore, by applying the suggested normalization, higher $\beta^{0}$ values obtained under steeper (closer to vertical) local incidence angles are divided by higher coefficient values compared to $\beta^{0}$ values acquired under shallower local incidence angles. The main difference between the $\sigma^{0}$ and $\beta^{0}$ methods is that the former applies a steeper increase to the radar backscatter $\left(\sigma^{0}\right)$ as the local incidence angle increases than the latter $\left(\beta^{0}\right)$. This difference in the behavior of the methods was created to take into account that as the incidence angle increases, the radar backscatter decreases more slowly for rough surfaces than for smooth surfaces $[90,100]$.

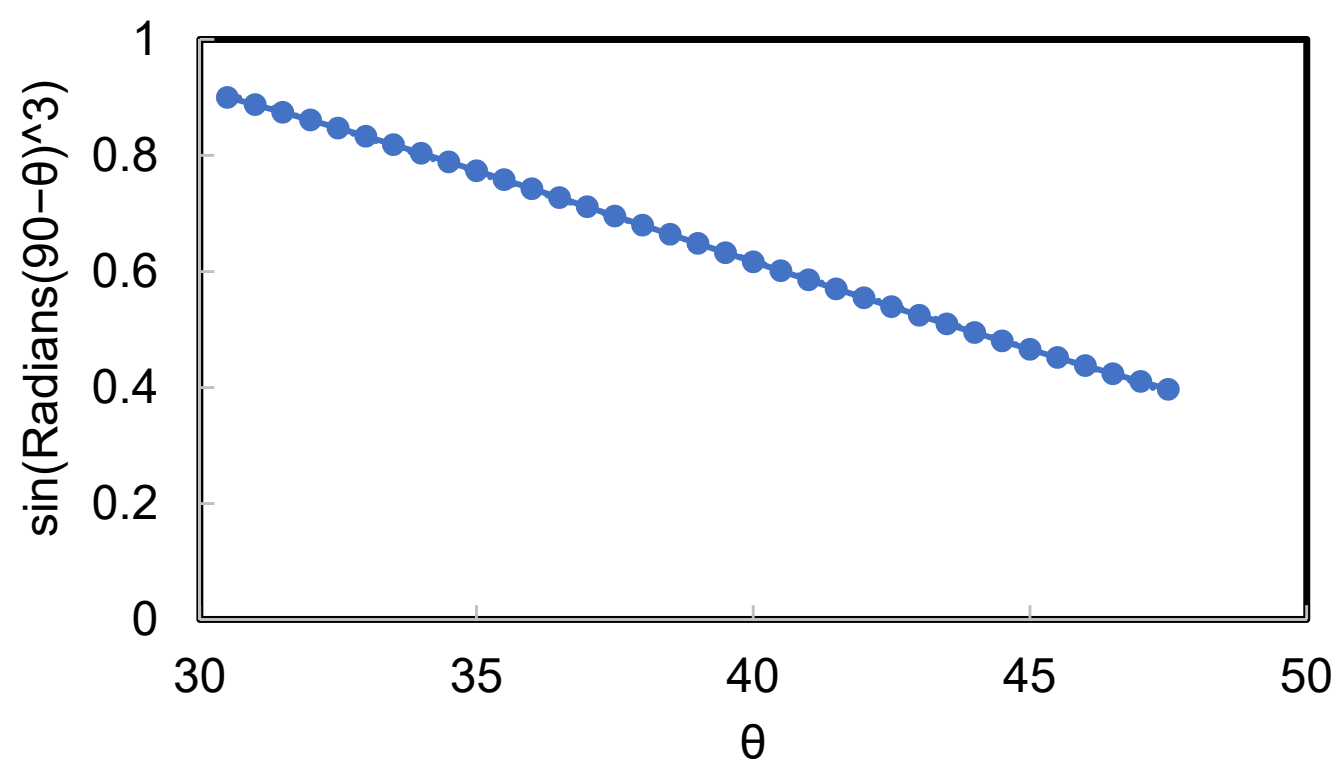

Figure 4. The attenuation coefficient $\left(\sin \left(\operatorname{Radians}(90-\theta)^{3}\right)\right)$, as a function of $\theta$ (in degrees), and the local incidence angle. This attenuation coefficient was used to correct for the dependence of radar brightness $\beta^{0}$ values on the local incidence angle.

Therefore, the normalized $\beta^{0}$ value can be written as

$$
\beta_{\text {Norm }}^{0}=\frac{\beta^{0}}{\sin \left(\text { Radians }(90-\theta)^{3}\right)}
$$

where $\beta_{\text {Norm }}^{0}$ is the normalized radar brightness in $\mathrm{VV}$ or $\mathrm{VH}$ polarization, $\beta^{0}$ is the radar brightness in $\mathrm{VV}$ or VH polarization, and $\sin \left(\operatorname{Radians}(90-\theta)^{3}\right)$ is the attenuation coefficient.

The processing tomato LAI model utilizes the sum of normalized $\beta^{0}$ in both polarizations:

$$
\mathrm{LAI}=\frac{\beta_{\mathrm{VH}}^{0}}{\sin \left(\operatorname{Radians}(90-\theta)^{3}\right)}+\frac{\beta_{\mathrm{VV}}^{0}}{\sin \left(\text { Radians }(90-\theta)^{3}\right)}
$$




\subsection{Calibration and Validation of Empirical Vegetation Variable Estimation Models}

The field-measured vegetation variables were used in regression models against the uncorrected radar backscatter parameters. Further, the proposed local incidence angle normalization methods were applied to the SAR images, and new empirical regression models were derived. Finally, the models based on the data prior to normalization and postnormalization and on the dual-polarized RVI were compared to assess the performance of the normalization process (Figure 5).

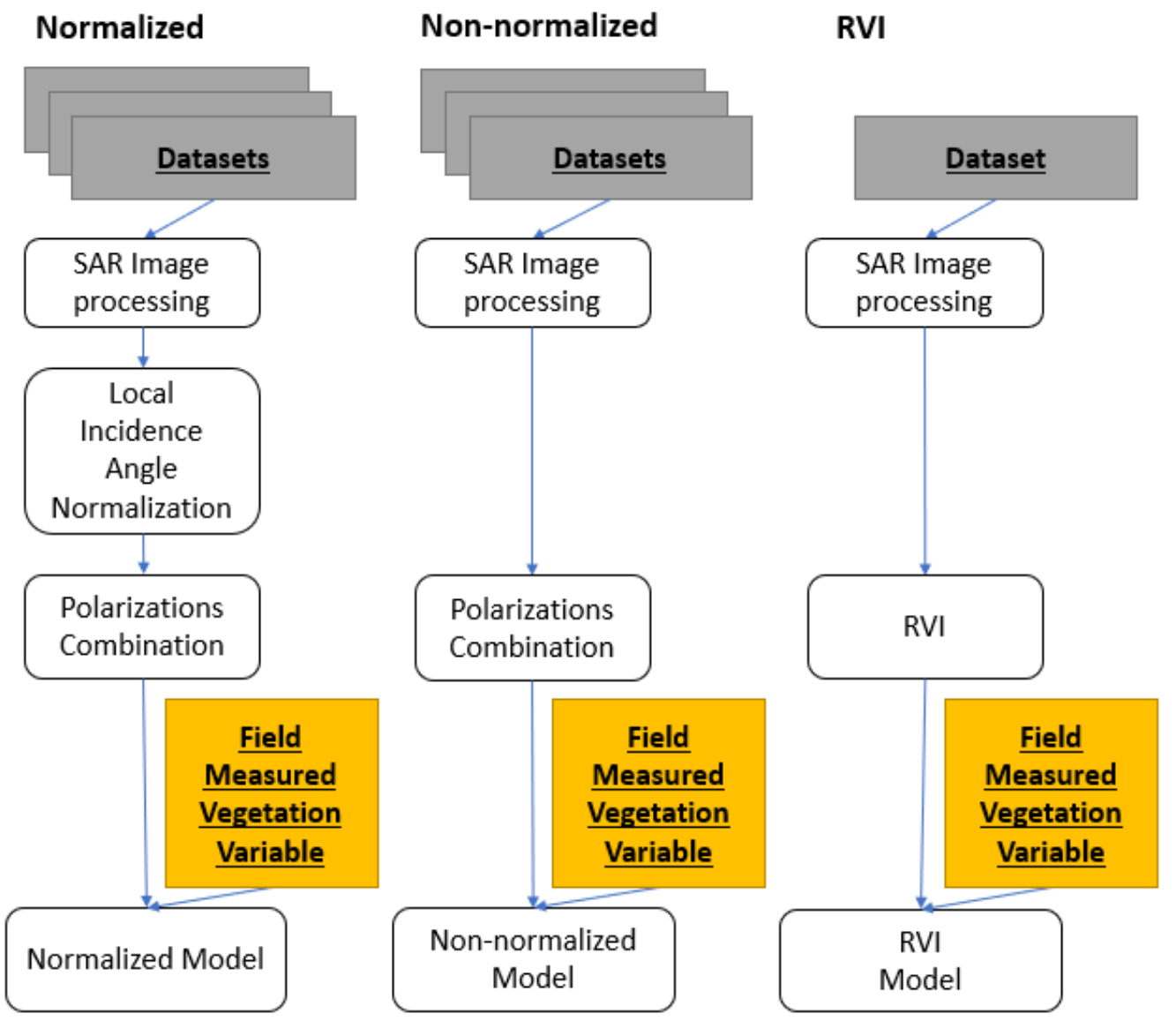

Figure 5. Derivation of the dual-polarized normalized (with $\sigma^{0}$ or $\beta^{0}$ normalization), non-normalized, and RVI models.

In every case, the same type of regression model (either linear or polynomial) and the same polarization combination were used in the comparison. Coefficients of determination in models based on non-normalized data were symbolized as $\mathrm{R}_{0}^{2}$, and their root-meansquare error was symbolized as RMSE $E_{0}$. The differences in the $\mathrm{R}^{2}$ and RMSE following the normalization procedures were calculated. In addition, the Steiger variation [101] of the two-tailed Fisher Z-score tests [102] was performed to determine whether the difference in the models' $R^{2}$ is significant $(\alpha \leq 0.05)$. The significance of the RMSE difference was calculated using the two-tailed Wilcoxon signed-rank test [103] to determine whether the difference in the models' RMSE was significant $(\alpha \leq 0.05)$. According to the goals set in this study and due to a finite amount of available SAR imagery and ground truth data, all the available data were used to calibrate the empirical models to achieve the models maximum reliability and estimation accuracy [104]. In order to additionally validate the models' estimation performance, the RMSE values of normalized models applied separately to each dataset (experiment) were also calculated and are presented in Tables S4-S8. 


\section{Results}

\subsection{Wheat, Processing Tomato, and Cotton Height, LAI, and $K_{c}$ Models Based on the $\sigma^{0}$} Normalization Method

The effect of the proposed normalization (Equation (2)) on the SAR backscatter from two incidence angles is illustrated in Figure 6. Following the normalization process, the difference is greatly reduced, and a considerable improvement in the $\mathrm{R}^{2}$ and RMSE of all the $\sigma^{0}$-based models is observed. In wheat, processing tomatoes, and cotton, the height, LAI, and $\mathrm{K}_{\mathrm{c}}$ models' $\mathrm{R}^{2}$ improved in the range of 0.0172-0.367, and the RMSE improved in the range of $5-52 \%$. Table 3, Tables S4-S6, and Figure 7 show the performance of $\sigma^{0}$-based height, LAI, and $\mathrm{K}_{\mathrm{c}}$ models in wheat, processing tomatoes, and cotton.
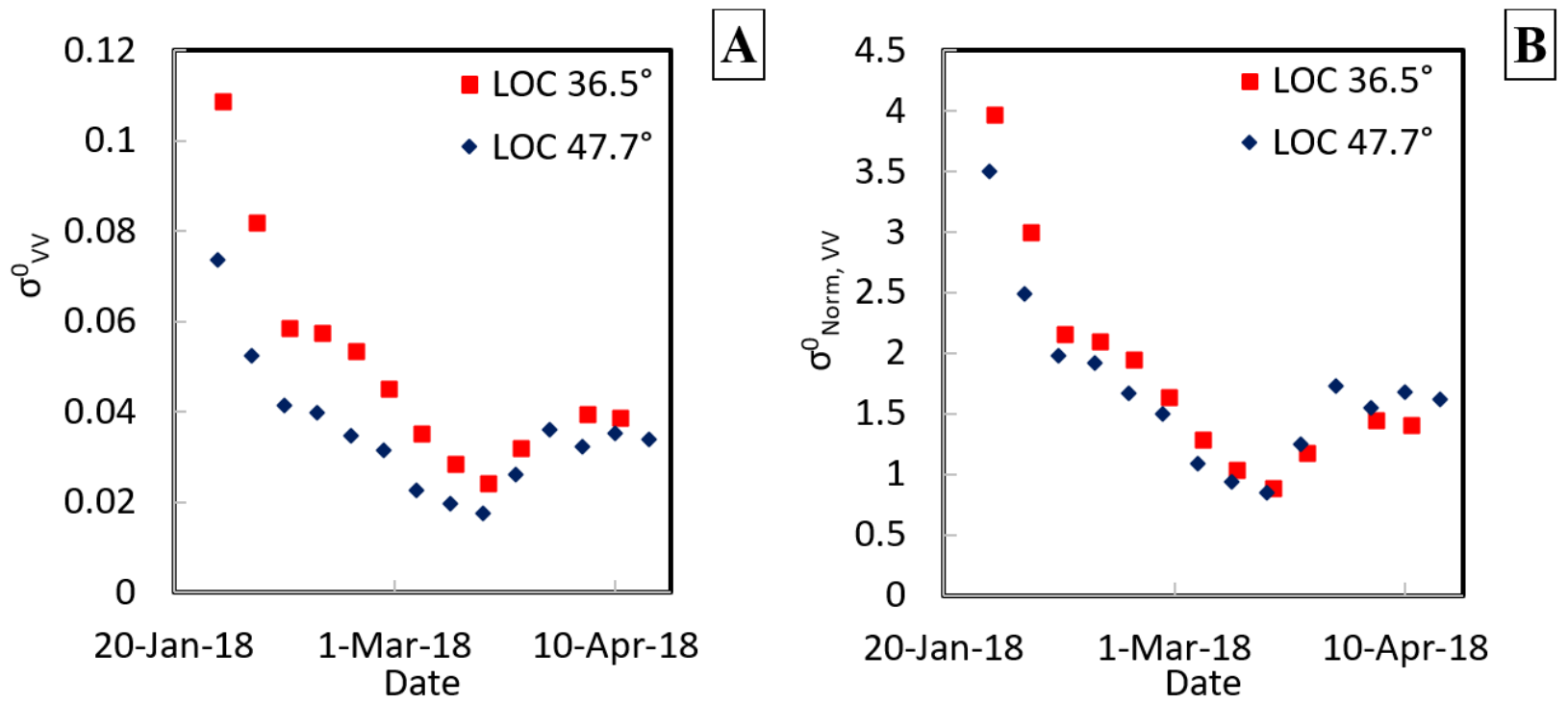

Figure 6. A time series of VV polarization values recorded by Sentinel-1 on its ascending overpasses with local incidence angles of $36.5^{\circ}$ and $47.7^{\circ}$ during the wheat experiment in Saad: (A) prior to applying the $\sigma^{0}$ normalization; (B) post-normalization.

Table 3. $\mathrm{R}^{2}$ and RMSE improvements following the local incidence angle normalization procedure. Significance is marked by *. The percentage values in the brackets show improvement in RMSE after normalization (i.e., the reduction in prediction error).

\begin{tabular}{|c|c|c|c|c|c|}
\hline Model & \# Images & $\mathbf{R}^{2}$ & RMSE & $R^{2}$ Improvement & RMSE Improvement (\%) \\
\hline Wheat height & 38 & 0.8566 & $6 \mathrm{~cm}$ & 0.0738 * & $2 \mathrm{~cm},(25 \%)$ \\
\hline Wheat LAI & 34 & 0.7194 & 0.6 & 0.1639 * & $0.2,(25 \%)$ \\
\hline Wheat $\mathrm{K}_{\mathrm{c}}$ & 11 & 0.6722 & 0.073 & 0.1601 & $0.016,(18 \%)$ \\
\hline Tomato $\mathrm{K}_{\mathrm{c}} \sigma^{0}$-based & 59 & 0.8549 & 0.0871 & 0.0172 & $0.005,(5 \%) *$ \\
\hline Tomato LAI $\sigma^{0}$-based & 50 & 0.7881 & 1.0 & 0.1001 & $1.1,(52 \%) *$ \\
\hline Tomato height $\sigma^{0}$-based & 94 & 0.4201 & $11 \mathrm{~cm}$ & 0.0446 & $1 \mathrm{~cm},(8 \%)$ \\
\hline Tomato $\mathrm{K}_{\mathrm{c}} \beta^{0}$-based & 59 & 0.871 & 0.0821 & $0.1143 *$ & $0.0307,(27 \%)$ \\
\hline Tomato LAI $\beta^{0}$-based & 50 & 0.8341 & 0.9 & $0.352 *$ & $0.7,(44 \%)$ \\
\hline Tomato height $\beta^{0}$-based & 94 & 0.8107 & $9 \mathrm{~cm}$ & $0.3442 *$ & $2 \mathrm{~cm},(18 \%)$ \\
\hline Cotton height $\sigma^{0}$-based & 11 & 0.8721 & $5 \mathrm{~cm}$ & $0.367 *$ & $5 \mathrm{~cm},(50 \%)$ \\
\hline Cotton $\mathrm{K}_{\mathrm{c}} \sigma^{0}$-based & 12 & 0.3742 & 0.0511 & $0.3543 *$ & $0.0128,(21 \%) *$ \\
\hline Cotton height $\beta^{0}$-based & 11 & 0.9467 & $8 \mathrm{~cm}$ & $0.668 *$ & $5 \mathrm{~cm},(38 \%)$ \\
\hline Cotton $\mathrm{K}_{\mathrm{c}} \beta^{0}$-based & 12 & 0.707 & 0.1293 & 0.6353 & $0.0379,(23 \%)^{*}$ \\
\hline
\end{tabular}



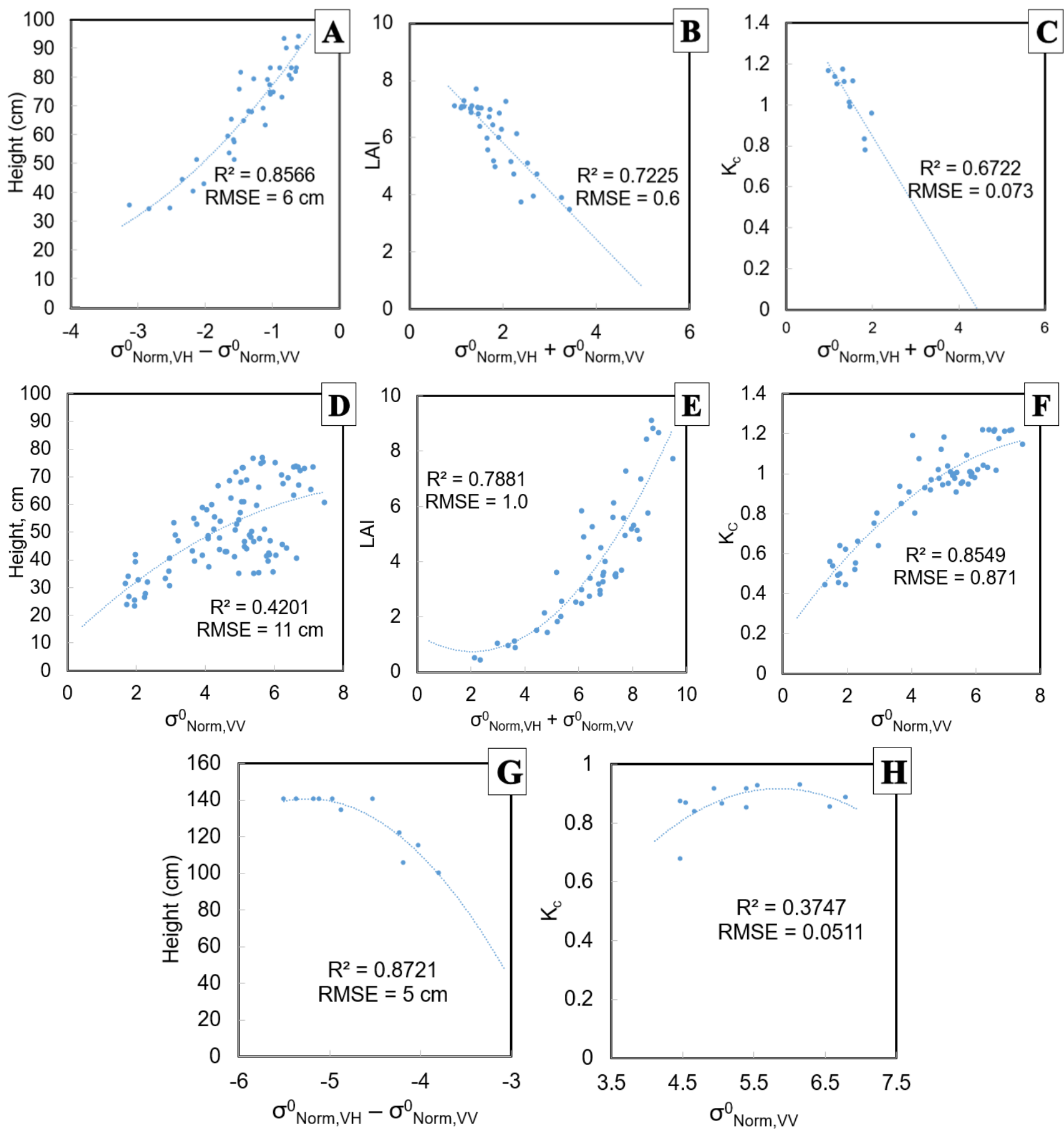

Figure 7. Models based on field measurements and the $\sigma^{0}$ normalization method: (A) wheat height; (B) wheat LAI; (C) wheat $\mathrm{K}_{\mathrm{c}}$; (D) processing tomato height; (E) processing tomato LAI; (F) processing tomato $\mathrm{K}_{\mathrm{c}}$; $(\mathrm{G})$ cotton height; (H) cotton $\mathrm{K}_{\mathrm{c}}$.

3.2. Processing Tomato and Cotton Height, LAI, and $K_{c}$ Models Based on the $\beta^{0}$ Normalization Method

The effect of the $\beta^{0}$-based normalization (Equation (8)) that reduces the difference in $\beta^{0}$ images acquired at different angles is shown in Figure 8. 

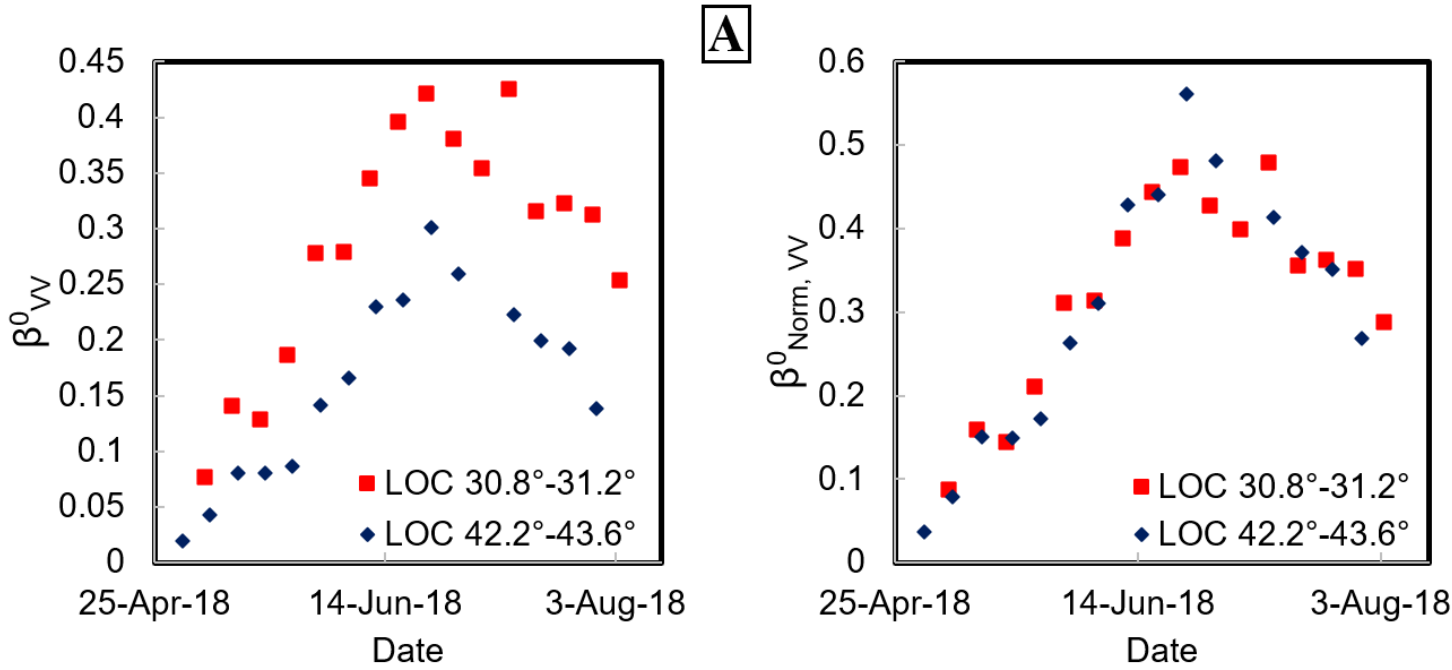

B

Figure 8. A time series of VV polarization values recorded by Sentinel-1 on its descending overpasses with local incidence angles in the ranges of $30.8^{\circ}-31.2^{\circ}$ and $42.2^{\circ}-43.6^{\circ}$ during the processing tomato experiment in Gadash, 2018: (A) prior to applying the $\beta^{0}$ normalization; (B) post-normalization.

The $\beta^{0}$-based normalization method permitted achieving the improvement in the $\mathrm{R}^{2}$ and RMSE of all the $\beta^{0}$-based models. For the processing tomato and cotton height, LAI, and $K_{c}$ models, the $R^{2}$ improved in the range of $0.1143-0.668$, and the RMSE improved in the range of 18-44\%. Table 3, Tables S7 and S8, and Figure 9 show the performance of processing tomato and cotton $\beta^{0}$-based height, LAI, and $\mathrm{K}_{\mathrm{c}}$ models. Table 3 shows the performance of all the $\sigma^{0}$-based and $\beta^{0}$-based normalized models developed in this study and their $\mathrm{R}^{2}$ and RMSE improvements over the non-normalized models.
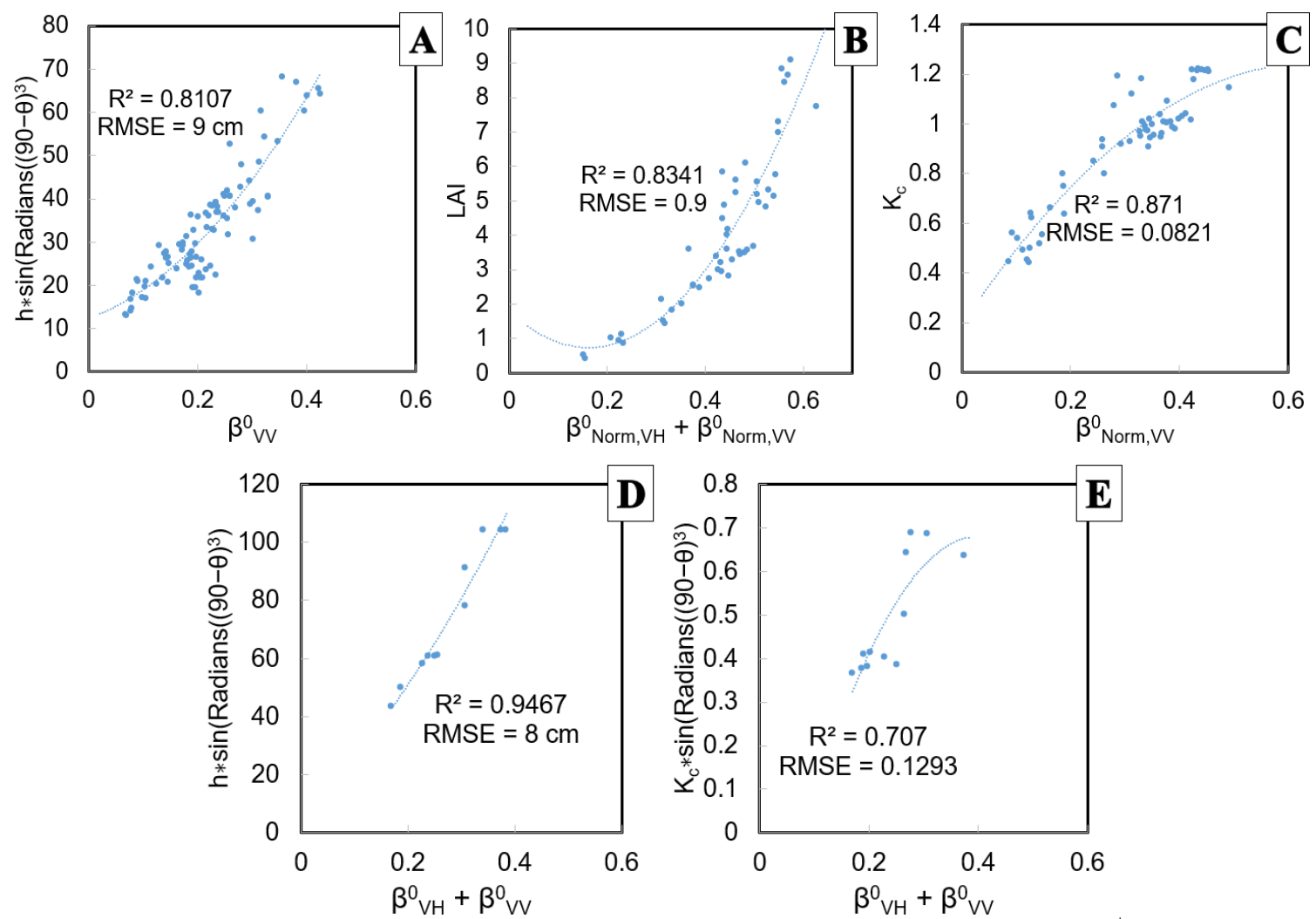

Figure 9. Models based on field measurements and the $\beta^{0}$ normalization method: (A) processing tomato height; (B) processing tomato LAI; (C) processing tomato $\mathrm{K}_{\mathrm{c}}$; (D) cotton height; $(\mathbf{E})$ cotton $\mathrm{K}_{\mathrm{c}}$. 


\subsection{Performance of the Dual-Polarized RVI}

The dual-polarized RVI-based wheat, processing tomato, and cotton models are shown in Table 4 . The wheat and cotton RVI models were compared against the $\sigma^{0}$-based models, while the processing tomato RVI models were compared to the $\beta^{0}$-based processing tomato models.

Table 4. RVI models for wheat, processing tomato, and cotton height, LAI, and $\mathrm{K}_{\mathrm{c}}$. The differences in $R^{2}$ and RMSE indicate the difference in performance compared to models based on either the $\sigma^{0}$ (wheat and cotton models) or $\beta^{0}$ (processing tomatoes) local incidence angle normalization methods in Table 3. Negative values represent lower $R^{2}$ and higher RMSE of the RVI models.

\begin{tabular}{|c|c|c|c|}
\hline & Height & LAI & $\mathbf{K}_{\mathrm{c}}$ \\
\hline \multicolumn{4}{|l|}{ Wheat } \\
\hline Overpass & Asc & Asc & Asc \\
\hline \# SAR images used & 26 & 25 & 6 \\
\hline Local incidence angle $\left({ }^{\circ}\right)$ & $35.3-36.6$ & $35.3-36.6$ & 47.7 \\
\hline $\mathrm{R}^{2}$ & 0.4248 & 0.1389 & 0.2912 \\
\hline$R^{2}$ difference & -0.2626 & -0.5805 & -0.381 \\
\hline RMSE & $13 \mathrm{~cm}$ & 1.6 & 0.102 \\
\hline RMSE difference & $-4 \mathrm{~cm}$ & -1.0 & -0.029 \\
\hline$(\%)$ & $(-44)$ & $(-167)$ & $(-40)$ \\
\hline \multicolumn{4}{|l|}{ Processing tomatoes } \\
\hline Overpass & Asc & Asc & Asc \\
\hline \# SAR images used & 25 & 31 & 27 \\
\hline Local incidence angle $\left(^{\circ}\right)$ & $42.0-43.1$ & $42.0-43.1$ & $\begin{array}{ll}42.0-43.1 \\
\end{array}$ \\
\hline $\mathrm{R}^{2}$ & 0.1584 & 0.3425 & 0.5635 \\
\hline$R^{2}$ difference & -0.6523 & -0.4916 & -0.3075 \\
\hline RMSE & $14 \mathrm{~cm}$ & 1.9 & 0.2488 \\
\hline RMSE difference & $-5 \mathrm{~cm}$ & -1.0 & -0.1667 \\
\hline$(\%)$ & $(-56)$ & $(-111)$ & $(-203)$ \\
\hline \multicolumn{4}{|l|}{ Cotton } \\
\hline Overpass & Asc & & \\
\hline \# SAR images used & 5 & & \\
\hline Local incidence angle $\left({ }^{\circ}\right)$ & 35.9 & & \\
\hline $\mathrm{R}^{2}$ & 0.3297 & & \\
\hline$R^{2}$ difference & -0.5424 & & \\
\hline RMSE & $12 \mathrm{~cm}$ & & \\
\hline RMSE difference & $-7 \mathrm{~cm}$ & & \\
\hline$(\%)$ & $(-140)$ & & \\
\hline
\end{tabular}

\section{Discussion}

In contrast with previous studies that mostly used images acquired under fixed or within narrow ranges of incidence angles, the correction derived in this study facilitates the use of imagery acquired under all typical geometrical conditions. By applying simple transformations to Sentinel- 1 imagery acquired under a wide range of incidence angles, the dependency of $\sigma^{0}$ and $\beta^{0}$ on the local incidence angle decreased, and the empirical modeling of several crop properties was improved. This achievement is remarkable because 
monitoring crops using the full temporal resolution of SAR imagery is much more useful than using imagery acquired at a narrow range of angles. Moreover, vegetation variable estimation models calibrated in one region using the proposed methods can be applied to other areas.

The improvement in the $\mathrm{R}^{2}$ and RMSE of the models following the local incidence angle normalization procedure was found to be significant in many of the models: wheat height and LAI models; $\beta^{0}$-based processing tomato LAI, height, and $\mathrm{K}_{\mathrm{c}}$ models; $\sigma^{0}$-based cotton $\mathrm{K}_{\mathrm{c}}$ and height models; and $\beta^{0}$-based cotton height model. Since the statistical significance of the difference between correlations is dependent on the number of images used for model development, some of the models yielded a difference that was not significant (wheat $\mathrm{K}_{\mathrm{c}}$ model, processing tomato $\sigma^{0}$-based LAI, height, and $\mathrm{K}_{\mathrm{c}}$ models, and cotton $\mathrm{K}_{\mathrm{c}}$ $\beta^{0}$-based model). However, the trend of improvement following the proposed normalization procedures is clear, and the practical usefulness of the proposed methods can be better represented by the RMSE improvements because RMSE represents the vegetation variable estimation accuracy. The RMSE improvement was found to be significant in the following models: processing tomato $\sigma^{0}$-based LAI and $\mathrm{K}_{\mathrm{c}}$ models; and cotton $\mathrm{K}_{\mathrm{c}} \sigma^{0}$ and $\beta^{0}$-based models. The RMSE improvement was not significant in the following models: wheat, processing tomato $\sigma^{0}$-based LAI, and processing tomato $\beta^{0}$-based models, and cotton height $\sigma^{0}$ - and $\beta^{0}$-based models. The $\mathrm{R}^{2}$ and RMSE of all the models calibrated in the present study improved following incidence angle normalization. The range of RMSE improvements varied from model to model (Table 3), from 5 to $52 \%$. Moreover, the performance of the newly developed $\beta^{0}$-based local incidence angle normalization method shows potential for overcoming the limitations of $\sigma^{0}$-based modeling for agricultural purposes. The use of $\beta^{0}$ to improve vegetation variable estimation is particularly useful in fields with a rough soil surface geometry. Using $\beta^{0}$ is not common for Sentinel-1 imagery, and the users' community could benefit from adopting this approach.

The models presented here for wheat and processing tomatoes were calibrated based on measurements taken throughout the entire duration of growing seasons and can, therefore, be applied at any time during crop development without restrictions. Nevertheless, the RMSE of LAI and height estimations was slightly higher at the peak of the season compared to the rest of the season. The relatively high accuracy of the models calibrated in this study and their independence from the incidence angle following the new normalization methods are advantageous compared to previous studies $[47,55,60,61,64]$, in which the images used were limited to a narrow range of incidence angles. In addition, in contrast to [48] that presented models that can only be reliably applied to certain vegetation heights, the wheat and processing tomato models presented here are applicable to any height within the range measured in our experiments: $34-95 \mathrm{~cm}$ (wheat) and $24-77 \mathrm{~cm}$ (processing tomatoes). A comparison between several studies that used C-band SAR to estimate vegetation height and LAI is shown in Tables 5 and 6.

The models for LAI estimation show a better performance than previous studies. Previous estimation based on imagery acquired under a narrow range of incidence angles and dual-polarization [47] only achieved $\mathrm{R}^{2}=0.25$. Moreover, the models in this study performed similarly to quad-polarization RADARSAT-2-based models for corn and soybean LAI estimation that utilized imagery acquired under a narrow range of incidence angles [39] and achieved $R^{2}=0.66$ and $\mathrm{RMSE}=0.75$ and $\mathrm{R}^{2}=0.64$ and $\mathrm{RMSE}=0.63$, respectively. Another study [60] presented a wheat LAI estimation model, which has better prediction performance than the models obtained in the present study (RMSE $=0.4$ ), but as in other previous models, it was based on images acquired under only one incidence angle. Unlike the LAI estimation based on optical imagery, the wheat and processing tomato LAI models developed in this study were not saturated even at the peak of vegetation development (wheat $\mathrm{LAI}_{\max }=7.7$, processing tomato $\mathrm{LAI}_{\max }=9.1$ ). Therefore, the LAI models in this paper might be applied throughout the whole season duration, which is useful because the LAI is a proxy for many vegetation variables [23], including crop productivity [105]. 
Table 5. Comparison of vegetation height estimation models based on Sentinel-1 and RISAT-1 C-band SAR.

\begin{tabular}{|c|c|c|c|c|c|}
\hline Model & Satellite & Crop & Incidence Angle $\left(^{\circ}\right)$ & $\mathbf{R}^{2}$ & Accuracy (RMSE) \\
\hline Wheat (this study) & Sentinel-1 & Wheat & $34.6-45.8$ & 0.8566 & $6 \mathrm{~cm}$ \\
\hline $\begin{array}{l}\text { Processing tomatoes } \sigma^{0} \text {-based } \\
\text { (this study) }\end{array}$ & Sentinel-1 & Tomato & $30.8-43.1$ & 0.4201 & $11 \mathrm{~cm}$ \\
\hline $\begin{array}{l}\text { Processing tomatoes } \\
\beta^{0} \text {-based (this study) }\end{array}$ & Sentinel-1 & Tomato & $30.8-43.1$ & 0.8107 & $9 \mathrm{~cm}$ \\
\hline Bousbih et al. (2017) [47] & Sentinel-1 & Cereals & $39-40$ & 0.54 & Not given \\
\hline Nasirzadehdizaji et al. (2019) [48] & Sentinel-1 & Wheat & $39-40$ & $\begin{array}{l}0.67(<53 \mathrm{~cm}) \\
0.07(\geq 53 \mathrm{~cm})\end{array}$ & Not given \\
\hline Srivastava (2019) [55] & RISAT-1 & Wheat & 31 & 0.37 & $18 \mathrm{~cm}$ \\
\hline Vreugdenhil et al. (2018) [64] & Sentinel-1 & Cereals & Constant & 0.68 & Not given \\
\hline Harfenmeister et al. (2019) [61] & Sentinel-1 & Wheat & Constant & 0.41 & Not given \\
\hline
\end{tabular}

Table 6. Comparison of vegetation LAI estimation models based on Sentinel-1 and RISAT-1 C-band SAR.

\begin{tabular}{llllll}
\hline Model & Satellite & Crop & Incidence Angle ${ }^{\circ}$ ) & $\mathbf{R}^{\mathbf{2}}$ & Accuracy (RMSE) \\
\hline Wheat (this study) & Sentinel-1 & Wheat & $34.6-45.8$ & 0.7225 & 0.6 \\
\hline $\begin{array}{l}\text { Processing tomatoes } \sigma^{0} \text {-based } \\
\text { this study) }\end{array}$ & Sentinel-1 & Tomato & $30.8-43.0$ & 0.7881 & 1.0 \\
\hline $\begin{array}{l}\text { Processing tomatoes } \beta^{0} \text {-based } \\
\text { this study) }\end{array}$ & Sentinel-1 & Tomato & $30.8-43.0$ & 0.8341 & 0.9 \\
\hline $\begin{array}{llll}\text { Chauhan et al. (2018) [60] } \\
\text { Bousbih et al. (2017) [47] }\end{array}$ & RISAT-1 & Wheat & 38 & 0.76 & 0.4 \\
\hline Vreugdenhil et al. (2018) [64] & Sentinel-1 & Cereals & $39-40$ & 0.25 & Not given \\
\hline Harfenmeister et al. (2019) [61] & Sentinel-1 & Wheat & Constant & 0.30 & Not given \\
\hline
\end{tabular}

The use of SAR for agricultural purposes has also been significantly enhanced by this study. While several previous studies used SAR to estimate the wheat LAI and crop height, processing tomatoes were not studied enough. Moreover, estimating $\mathrm{K}_{\mathrm{c}}$ of wheat, processing tomatoes, and cotton by SAR, to the best of our knowledge, was not previously conducted. Previously, the crop water requirement estimation of maize, soybean, pasture, and bean using SAR imagery acquired under a narrow range of incidence angles was conducted [49]. Another study showed a non-crop-specific region-wise correlation between only one Sentinel-1 image and the crop water stress index derived through the LANDSAT- 8 image [106]. Finally, [107] used smoothed time series of Sentinel-1 backscatter values in different polarization combinations to estimate $\mathrm{K}_{\mathrm{c}}$ in vineyards. Therefore, the wheat and processing tomato $K_{c}$ estimation models derived in this study pave the way to accurate $\mathrm{K}_{\mathrm{c}}$ estimation using all available SAR imagery. This study stands out by overcoming the limits imposed by the range of incidence angles typical for SAR imagery. As a result, the newly developed normalized wheat and processing tomato $\mathrm{K}_{\mathrm{c}}$ estimation models can be used with confidence during the entire duration of a growing season.

Although the cotton models calibrated in this study showed good performance, they are based on the data recorded from the middle to late stages of growing seasons. Therefore, future studies should improve upon this by including the early stages of the growing seasons. In addition, we did not calibrate an LAI model for cotton in this paper, but this should be feasible given good field measurements. Therefore, additional field experiments should be carried out to calibrate models for crop variables throughout the growing season. Even though the cotton models developed in this study might have only limited use, all four cotton models showed a sizeable improvement in the $\mathrm{R}^{2}$ and RMSE over the non- 
normalized models. This result confirms the effectiveness of the novel angle normalization approach suggested in the present study.

The performance of models based on the new transformation was favorable compared to models based on the dual-polarized RVI. Although the RVI-based models in the present study were calibrated under the most favorable conditions possible, using only ascending overpass imagery acquired under only one incidence angle, the new models based on local incidence angle normalization methods outperformed them: the RMSE of RVI-based models was 40-203\% higher. It should be noted that the assumption $\sigma_{\mathrm{VV}}^{0} \approx \sigma_{\mathrm{HH}}^{0}$ underlying the dual-polarized RVI is in contradiction to previous findings that show a typical difference of $5 \mathrm{~dB}$ between $\sigma_{\mathrm{VV}}^{0}$ and $\sigma_{\mathrm{HH}}^{0}$ in the intermediate range of incidence angles in the $C$ band $[91,108,109]$. Therefore, we conclude that the dual-polarized RVI is not recommended where the assumption of the equality of backscatter in the two polarizations cannot be made.

Unlike previous studies that used only fields with rows perpendicular to the SAR beam [110], in this study, all the fields were used in model calibration. While this row geometry is less noticeable in wheat fields, particularly in the middle and later stages of the season, it should be noted that cotton and processing tomatoes are planted in rows of earth mounds with furrows between them. In addition, the spatial orientation of the rows in the fields in this study was not uniform between the locations. For example, in the processing tomato fields in Gadash, the rows were oriented from west to east, while in Gadot, the orientation was from west-southwest to east-northeast. This difference in the spatial orientation of rows affects the backscatter because the target's radar crosssection depends on its angle relative to the satellite [111], and even minimal changes in the target aspect significantly affect the RCS [112,113]. Nevertheless, the processing tomato models were not sensitive to the crop row orientation because they showed a similar RMSE (Tables S5 and S7) when they were applied to different fields. Therefore, the proposed models seem to be insensitive to the row orientation and could likely be used in other fields with different row orientations relative to the satellite orbit. However, this should be further tested in future studies.

Despite the overall reliable performance of the newly developed models, it should be pointed out that winter images in descending orbits have much weaker correlations with the vegetation height, $\mathrm{LAI}$, and $\mathrm{K}_{\mathrm{c}}$ compared to images from ascending orbits. Consequently, SAR images acquired in descending orbits could not be used for the development of the wheat model. In the summer crops tested in this study, this phenomenon did not occur, rendering the imagery acquired from descending orbits usable for the modeling of crop variables.

A likely explanation for the weaker performance of wheat models based on imagery from descending orbits might be related to the higher relative humidity in the early morning (descending images were acquired around 03:40 GMT) compared to the relative humidity in the evening (ascending images were acquired around 15:40 GMT). This observation is confirmed by our meteorological measurements in Saad and Kvutsat Yavne, which showed a regular diurnal pattern of a decrease in relative humidity following sunrise: from up to $100 \%$ in early morning hours to $40-60 \%$ in the afternoons. At night and in the early morning, the relative humidity is very high, and the formation of fog and dew, along with increased topsoil moisture, causes increased scattering and attenuation of the SAR beam $[114,115]$. Additionally, the SAR beam can be affected by common atmospheric inhomogeneities in the morning hours over Israel that create radar echoes [116] and increase the atmospheric reflectance and attenuation of the transmitted energy [117]. In previous studies, datasets affected by these effects were binned. For example, [61] omitted a dataset that was affected by dew. The issue of the relatively lower performance of descending orbit-based models is an interesting direction that can be studied by analyzing data from other regions and coupling them with the complementary ground and atmospheric measurements.

Although the newly proposed local incidence angle normalization methods were tested on the typical incidence angle range of Sentinel-1 and most other spaceborne SAR 
missions, they are not expected to be effective for very steep incidence angles near to the "nadir hole" region [118] or for very shallow angles because of the non-linear dependence of the radar backscatter on the incidence angle in these ranges [90,91].

The proposed $\sigma^{0}$ local incidence angle normalization method can be used not only for agricultural purposes but also for other SAR applications. Additional studies need to be carried out to determine if this method is ideal for general use. The $\beta^{0}$ local incidence angle normalization method might be used for the vegetation variable estimation of crops other than processing tomatoes and cotton grown on rough soil surfaces. Future studies should pursue this.

\section{Conclusions}

The proposed $\sigma^{0}$ and $\beta^{0}$ local incidence angle normalization methods facilitate the use of all the images acquired by the Sentinel- 1 constellation under the full range of typical incidence angles. This is supported by an improvement in the correlations between the SAR measurements and crop variables such as LAI, crop height, and $\mathrm{K}_{\mathrm{c}}$ following these normalization procedures in three crops: cotton, tomatoes, and wheat. Models based on the suggested normalization of the incidence angle show considerable $R^{2}$ and RMSE improvements over the models that were not based on these transformations. This increase in performance is the most notable for the wheat height and LAI models, processing tomato $\sigma^{0}$-based LAI and $\beta^{0}$-based height models, and the cotton models. Most $\mathrm{K}_{\mathrm{c}}, \mathrm{LAI}$, and height models worked well with imagery acquired from ascending and descending orbits, but winter imagery performed better with ascending orbits. This approach to estimate vegetation variables is useful for routine vegetation and agricultural monitoring, having a higher temporal resolution and accuracy than the previous approaches. Despite these results, we wish to stress that the most important achievement is not only the improvement in the models' performance but also the enablement of the conjoint use of images acquired under different incidence angles and even different orbits.

Supplementary Materials: The following are available online at https:/ /www.mdpi.com/article/10 .3390/land10070680/s1; Table S1: Sentinel-1 image inventory used in the development of models for wheat. Each line represents a dataset with specific geometrical parameters; Table S2: Sentinel-1 image inventory used in the development of models for cotton. Each line represents a dataset with specific geometrical parameters; Table S3: Sentinel-1 image inventory used in the development of models for processing tomatoes. Each line represents a dataset with specific geometrical parameters; Table S4: Wheat height, LAI, and $\mathrm{K}_{\mathrm{c}}$ models; Table S5: Processing tomato height, LAI, and $\mathrm{K}_{\mathrm{c}}$ models based on the $\sigma^{0}$ normalization method; Table S6: Cotton height and $\mathrm{K}_{\mathrm{c}}$ models based on the $\sigma^{0}$ normalization method; Table S7: Processing tomato height, LAI, and $\mathrm{K}_{\mathrm{c}}$ models based on the $\beta^{0}$ normalization methods; Table S8: Cotton height and $\mathrm{K}_{\mathrm{c}}$ models based on the $\beta^{0}$ normalization method.

Author Contributions: Conceptualization, O.R., G.K.; methodology, G.K., software, G.K., L.F., V.L.; validation, G.K.; formal analysis, G.K.; investigation, G.K.; fieldwork, G.K., V.L., L.F., V.S.M.; writing—original draft preparation, G.K., O.R.; writing—review and editing, O.R., G.K., V.S.M., J.T.; visualization, G.K., V.S.M., O.R.; supervision, O.R.; project administration, O.R., J.T.; funding acquisition, O.R., J.T. All authors have read and agreed to the published version of the manuscript.

Funding: The cotton field measurements were funded by the Chief Scientist of the Ministry of Agriculture, Israel, under grant number 304-0505, and the wheat and tomato field measurements were funded by the Ministry of Science and Technology, Israel, under grant numbers 3-14559, 3-15605. Gregoriy Kaplan was supported by an absorption grant for new immigrant scientists provided by the Israeli Ministry of Immigrant Absorption. Manivasagam V.S. was supported by the ARO Postdoctoral Fellowship Program from the Agriculture Research Organization, Volcani Institute, Israel.

Institutional Review Board Statement: Not applicable.

Informed Consent Statement: Not applicable.

Data Availability Statement: Sentinel-1 data were obtained from the ESA Copernicus Open Access Hub website (https:/ / scihub.copernicus.eu/dhus/\#/home, accessed on 26 June 2021). 
Acknowledgments: We thank Leonid Dinevich from Tel-Aviv University for his helpful advice. We thank Nitai Haymann for his contribution to software processing and fieldwork. We thank all the growers. We also thank the reviewers.

Conflicts of Interest: The authors declare no conflict of interest.

\section{References}

1. Broge, N.H.; Thomsen, A.G.; Andersen, P.B. Comparison of Selected Vegetation Indices as Indicators of Crop Status. Available online: http:/ / www.earsel.org/symposia/2002-symposium-Prague/pdf/083.pdf (accessed on 24 June 2021).

2. González-Dugo, M.P.; Mateos, L. Spectral vegetation indices for benchmarking water productivity of irrigated cotton and sugarbeet crops. Agric. Water Manag. 2008, 95, 48-58. [CrossRef]

3. Johnson, L.F.; Trout, T.J. Satellite NDVI Assisted Monitoring of Vegetable Crop Evapotranspiration in California's San Joaquin Valley. Remote Sens. 2012, 4, 439-455. [CrossRef]

4. Mróz, M.; Sobieraj, A. Comparison of several vegetation indices calculated on the basis of a seasonal SPOT XS time series, and their suitability for land cover and agricultural crop identification. Technol. Sci. 2004, 7, 39-66. [CrossRef]

5. Purevdorj, T.S.; Tateishi, R.; Ishiyama, T.; Honda, Y. Relationships between percent vegetation cover and vegetation indices. Int. J. Remote Sens. 1998, 19, 3519-3535. [CrossRef]

6. Rozenstein, O.; Haymann, N.; Kaplan, G.; Tanny, J. Estimating cotton water consumption using a time series of Sentinel-2 imagery. Agric. Water Manag. 2018, 207, 44-52. [CrossRef]

7. Santos, C.L.M.d.O.; Lamparelli, R.A.C.; Figueiredo, G.K.D.A.; Dupuy, S.; Boury, J.; Luciano, A.C.d.S.; Torres, R.d.S.; le Maire, G. Classification of crops, pastures, and tree plantations along the season with multi-sensor image time series in a subtropical agricultural region. Remote Sens. 2019, 11, 334. [CrossRef]

8. Viña, A.; Gitelson, A.A.; Nguy-Robertson, A.L.; Peng, Y. Comparison of different vegetation indices for the remote assessment of green leaf area index of crops. Remote Sens. Environ. 2011, 115, 3468-3478. [CrossRef]

9. Nguy-Robertson, A.L.; Peng, Y.; Gitelson, A.A.; Arkebauer, T.J. Agricultural and Forest Meteorology Estimating green LAI in four crops Potential of determining optimal spectral bands for a universal algorithm. Agric. For. Meteorol. J. 2014, 192-193, 140-148. [CrossRef]

10. Rozenstein, O.; Qin, Z.; Derimian, Y.; Karnieli, A. Derivation of land surface temperature for Landsat-8 TIRS using a split window algorithm. Sensors 2014, 14, 5768-5780. [CrossRef]

11. Manivasagam, V.S.; Kaplan, G.; Rozenstein, O. Developing Transformation Functions for VEN $\mu$ S and Sentinel-2 Surface Reflectance over Israel. Remote Sens. 2019, 11, 1710. [CrossRef]

12. Flood, N. Continuity of reflectance data between Landsat-7 ETM+ and Landsat-8 OLI, for both top-of-atmosphere and surface reflectance: A study in the Australian landscape. Remote Sens. 2014, 6, 7952-7970. [CrossRef]

13. Bannari, A. Synergy Between Sentinel-MSI and Landsat-OLI to Support High Temporal Frequency for Soil Salinity Monitoring in an Arid Landscape. Res. Dev. Saline Agric. 2019. [CrossRef]

14. Padró, J.C.; Pons, X.; Aragonés, D.; Díaz-Delgado, R.; García, D.; Bustamante, J.; Pesquer, L.; Domingo-Marimon, C.; GonzálezGuerrero, Ò.; Cristóbal, J.; et al. Radiometric correction of simultaneously acquired Landsat-7/Landsat-8 and Sentinel-2A imagery using Pseudoinvariant Areas (PIA): Contributing to the Landsat time series legacy. Remote Sens. 2017, 9, 1319. [CrossRef]

15. Kaplan, G.; Fine, L.; Lukyanov, V.; Manivasagam, V.S.; Malachy, N.; Tanny, J.; Rozenstein, O. Estimating Processing Tomato Water Consumption, Leaf Area Index, and Height Using Sentinel-2 and VEN $\mu$ S Imagery. Remote Sens. 2021, 13, 1046. [CrossRef]

16. Asrar, G.; Fuchs, M.; Kanemasu, E.T.; Hatfield, J.L. Estimating Absorbed Photosynthetic Radiation and Leaf Area Index from Spectral Reflectance in Wheat. Agron. J. 1984, 76, 300. [CrossRef]

17. Reichenau, T.G.; Korres, W.; Montzka, C.; Fiener, P.; Wilken, F.; Stadler, A.; Waldhoff, G.; Schneider, K. Spatial heterogeneity of Leaf Area Index (LAI) and its temporal course on arable land: Combining field measurements, remote sensing and simulation in a Comprehensive Data Analysis Approach (CDAA). PLoS ONE 2016, 11, 1-24. [CrossRef] [PubMed]

18. Sun, Y.; Qin, Q.; Ren, H.; Zhang, T.; Chen, S. Red-Edge Band Vegetation Indices for Leaf Area Index Estimation from Sentinel2/MSI Imagery. IEEE Trans. Geosci. Remote Sens. 2020, 58, 826-840. [CrossRef]

19. Wang, C.; Feng, M.C.; Yang, W.D.; Ding, G.W.; Sun, H.; Liang, Z.Y.; Xie, Y.K.; Qiao, X.X. Impact of spectral saturation on leaf area index and aboveground biomass estimation of winter wheat. Spectrosc. Lett. 2016, 49, 241-248. [CrossRef]

20. Kaplan, G.; Rozenstein, O. Spaceborne Estimation of Leaf Area Index in Cotton, Tomato, and Wheat Using Sentinel-2. Land 2021, 10, 505. [CrossRef]

21. Simic Milas, A.; Romanko, M.; Reil, P.; Abeysinghe, T.; Marambe, A. The importance of leaf area index in mapping chlorophyll content of corn under different agricultural treatments using UAV images. Int. J. Remote Sens. 2018, 39, 5415-5431. [CrossRef]

22. Ewert, F. Modelling plant responses to elevated CO2: How important is leaf area index? Ann. Bot. 2004, 93, 619-627. [CrossRef]

23. Herrmann, I.; Pimstein, A.; Karnieli, A.; Cohen, Y.; Alchanatis, V.; Bonfil, D.J. LAI assessment of wheat and potato crops by VEN $\mu \mathrm{S}$ and Sentinel-2 bands. Remote Sens. Environ. 2011, 115, 2141-2151. [CrossRef]

24. Heuvelink, E.; Bakker, M.J.; Elings, A.; Kaarsemaker, R.; Marcelis, L.F.M. Effect of leaf area on tomato yield. Acta Hortic. 2005, 691, 43-50. [CrossRef] 
25. Sadeh, Y.; Zhu, X.; Dunkerley, D.; Walker, J.P.; Zhang, Y.; Rozenstein, O.; Manivasagam, V.S.; Chenu, K. Fusion of Sentinel-2 and PlanetScope time-series data into daily $3 \mathrm{~m}$ surface reflectance and wheat LAI monitoring. Int. J. Appl. Earth Obs. Geoinf. 2021, 96, 102260. [CrossRef]

26. Manivasagam, V.S.; Rozenstein, O. Practices for upscaling crop simulation models from field scale to large regions. Comput. Electron. Agric. 2020, 175, 105554. [CrossRef]

27. Manivasagam, V.S.; Sadeh, Y.; Kaplan, G.; Bonfil, D.J.; Rozenstein, O. Studying the Feasibility of Assimilating Sentinel-2 and PlanetScope Imagery into the SAFY Crop Model to Predict Within-Field Wheat Yield. Remote Sens. 2021, 13, 2395. [CrossRef]

28. Qi, J.; Wang, C.; Inoue, Y.; Zhang, R.; Gao, W. Synergy of optical and radar remote sensing in agricultural applications. Ecosyst. Dyn. Agric. Remote Sens. Model. Site-Specific Agric. 2004, 5153, 153. [CrossRef]

29. Luo, P.; Liao, J.; Shen, G. Combining Spectral and Texture Features for Estimating Leaf Area Index and Biomass of Maize Using Sentinel-1/2, and Landsat-8 Data. IEEE Access 2020, 8, 53614-53626. [CrossRef]

30. Jin, X.; Yang, G.; Xu, X.; Yang, H.; Feng, H.; Li, Z.; Shen, J.; Zhao, C.; Lan, Y. Combined multi-temporal optical and radar parameters for estimating LAI and biomass in winter wheat using HJ and RADARSAR-2 data. Remote Sens. 2015, 7, 13251-13272. [CrossRef]

31. Wang, J.; Xiao, X.; Bajgain, R.; Starks, P.; Steiner, J.; Doughty, R.B.; Chang, Q. Estimating leaf area index and aboveground biomass of grazing pastures using Sentinel-1, Sentinel-2 and Landsat images. ISPRS J. Photogramm. Remote Sens. 2019, 154, $189-201$. [CrossRef]

32. Reamer, R.E.; Stockton, W.O.; Stromfors, R.D. New military uses for Synthetic Aperture Radar (SAR). Airborne Reconnaiss. XVI 1993, 113-119. [CrossRef]

33. Allen, R.G.; Pereira, L.S.; Dirk, R.; Smith, M. Crop Evapotranspiration-Guidelines For Computing Crop Water Requirements-FAO Irrigation And Drainage Paper 56; FAO: Rome, Italy, 1998; Volume 300, p. D05109. Available online: http://www.fao.org/3/X049 0E/X0490E00.htm (accessed on 24 June 2021).

34. Pereira, L.S.; Paredes, P.; Hunsaker, D.J.; López-Urrea, R.; Mohammadi Shad, Z. Standard single and basal crop coefficients for field crops. Updates and advances to the FAO56 crop water requirements method. Agric. Water Manag. 2021, 243, 1-35. [CrossRef]

35. Trevisan, R.G.; Junior, N.d.S.V.; Portz, G.; Eitelwein, M.T.; Molin, J.P. Use of crop height and optical sensor readings to predict mid-season cotton biomass. In Proceedings of the Precision agriculture '15, Volcani Center, Israel, 12-16 July $2015 ;$ p. 8.

36. Asilo, S.; Nelson, A.; Bie, K.D.; Skidmore, A.; Laborte, A.; Maunahan, A.; Quilang, E.J.P. Relating X-band SAR Backscattering to Leaf Area Index of Rice in Different Phenological Phases. Remote Sens. 2019, 11, 1462. [CrossRef]

37. Canisius, F.; Shang, J.; Liu, J.; Huang, X.; Ma, B.; Jiao, X.; Geng, X.; Kovacs, J.M.; Walters, D. Tracking crop phenological development using multi-temporal polarimetric Radarsat-2 data. Remote Sens. Environ. 2018, 210, 508-518. [CrossRef]

38. McNairn, H.; Champagne, C.; Shang, J.; Holmstrom, D.; Reichert, G. Integration of optical and Synthetic Aperture Radar (SAR) imagery for delivering operational annual crop inventories. ISPRS J. Photogramm. Remote Sens. 2009, 64, 434-449. [CrossRef]

39. Hosseini, M.; McNairn, H.; Merzouki, A.; Pacheco, A. Estimation of Leaf Area Index (LAI) in corn and soybeans using multipolarization C- and L-band radar data. Remote Sens. Environ. 2015, 170, 77-89. [CrossRef]

40. Kim, Y.; Jackson, T.; Bindlish, R.; Lee, H.; Hong, S. Radar vegetation index for estimating the vegetation water content of rice and soybean. IEEE Geosci. Remote Sens. Lett. 2012, 9, 564-568. [CrossRef]

41. Small, D. Flattening Gamma: Radiometric Terrain Correction for SAR Imagery. IEEE Trans. Geosci. Remote Sens. 2011, 49, 3081-3093. [CrossRef]

42. Makynen, M.; Karvonen, J. Incidence angle dependence of first-year sea ice backscattering coefficient in Sentinel-1 SAR imagery over the Kara Sea. IEEE Trans. Geosci. Remote Sens. 2017, 55, 6170-6181. [CrossRef]

43. Widhalm, B.; Bartsch, A.; Goler, R. Simplified normalization of C-band synthetic aperture radar data for terrestrial applications in high latitude environments. Remote Sens. 2018, 10, 1-18. [CrossRef]

44. Van Tricht, K.; Gobin, A.; Gilliams, S.; Piccard, I. Synergistic Use of Radar Sentinel-1 and Optical Sentinel-2 Imagery for Crop Mapping: A Case Study for Belgium. Remote Sens. 2018, 10, 1642. [CrossRef]

45. Inoue, Y.; Sakaiya, E.; Wang, C. Capability of C-band backscattering coefficients from high-resolution satellite SAR sensors to assess biophysical variables in paddy rice. Remote Sens. Environ. 2014, 140, 257-266. [CrossRef]

46. Veloso, A.; Mermoz, S.; Bouvet, A.; Le Toan, T.; Planells, M.; Dejoux, J.F.; Ceschia, E. Understanding the temporal behavior of crops using Sentinel-1 and Sentinel-2-like data for agricultural applications. Remote Sens. Environ. 2017, 199, 415-426. [CrossRef]

47. Bousbih, S.; Zribi, M.; Lili-Chabaane, Z.; Baghdadi, N.; El Hajj, M.; Gao, Q.; Mougenot, B. Potential of Sentinel-1 Radar Data for the Assessment of Soil and Cereal Cover Parameters. Sensors 2017, 17, 2617. [CrossRef] [PubMed]

48. Nasirzadehdizaji, R.; Balik Sanli, F.; Abdikan, S.; Cakir, Z.; Sekertekin, A.; Ustuner, M. Sensitivity Analysis of Multi-Temporal Sentinel-1 SAR Parameters to Crop Height and Canopy Coverage. Appl. Sci. 2019, 9, 655. [CrossRef]

49. Navarro, A.; Rolim, J.; Miguel, I.; Catalão, J.; Silva, J.; Painho, M.; Vekerdy, Z. Crop Monitoring Based on SPOT-5 Take-5 and Sentinel-1A Data for the Estimation of Crop Water Requirements. Remote Sens. 2016, 8, 525. [CrossRef]

50. Inglada, J.; Vincent, A.; Arias, M.; Marais-Sicre, C. Improved early crop type identification by joint use of high temporal resolution SAR and optical image time series. Remote Sens. 2016, 8, 362. [CrossRef]

51. Hosseini, M.; McNairn, H.; Mitchell, S.; Davidson, A.; Robertson, L.D. Combination of optical and SAR sensors for monitoring biomass over corn fields. Int. Geosci. Remote Sens. Symp. 2018, 2018, 5952-5955. [CrossRef] 
52. Phan, H.; Le Toan, T.; Bouvet, A. Understanding Dense Time Series of Sentinel-1 Backscatter from Rice Fields: Case Study in a Province of the Mekong Delta, Vietnam. Remote Sens. 2021, 13, 921. [CrossRef]

53. Molijn, R.; Iannini, L.; Vieira Rocha, J.; Hanssen, R. Sugarcane Productivity Mapping through C-Band and L-Band SAR and Optical Satellite Imagery. Remote Sens. 2019, 11, 1109. [CrossRef]

54. Demarez, V.; Helen, F.; Marais-Sicre, C.; Baup, F. In-Season Mapping of Irrigated Crops Using Landsat 8 and Sentinel-1 Time Series. Remote Sens. 2019, 11, 118. [CrossRef]

55. Srivastava, H.S.; Sivasankar, T. Potential of C-Band Hybrid Polarimetric RISAT-1 SAR Data To Estimate Wheat Crop Height. In Proceedings of the ISPRS-GEOGLAM-ISRS International Workshop on 'Earth Observations for Agricultural Monitoring', New Delhi, India, 18-20 February 2019.

56. Srivastava, H.S.; Sivasankar, T.; Patel, P. The sensitivity of C-band hybrid polarimetric RISAT-1 SAR data to leaf area index of paddy crop. ISPRS Ann. Photogramm. Remote Sens. Spat. Inf. Sci. 2018, 4, 215-222. [CrossRef]

57. Benabdelouahab, T.; Dominique, D.; Hayat, L.; Hadria, R.; Tychon, B.; Boudhar, A.; Balaghi, R.; Lebrini, Y.; Maaroufi, H.; Barbier, C. Using SAR Data to Detect Wheat Irrigation Supply in an Irrigated Semi-arid Area. J. Agric. Sci. 2018, 11, 1916-9760. [CrossRef]

58. Han, D.; Liu, S.; Du, Y.; Xie, X.; Fan, L.; Lei, L.; Li, Z.; Yang, H.; Yang, G. Crop Water Content of Winter Wheat Revealed with Sentinel-1 and Sentinel-2 Imagery. Sensors 2019, 19, 4013. [CrossRef]

59. Yadav, V.P.; Prasad, R.; Bala, R. Leaf area index estimation of wheat crop using modified water cloud model from the time-series SAR and optical satellite data. Geocarto Int. 2019, 36, 791-802. [CrossRef]

60. Chauhan, S.; Srivastava, H.S.; Patel, P. Wheat crop biophysical parameters retrieval using hybrid-polarized RISAT-1 SAR data. Remote Sens. Environ. 2018, 216, 28-43. [CrossRef]

61. Harfenmeister, K.; Spengler, D.; Weltzien, C. Analyzing temporal and spatial characteristics of crop parameters using Sentinel-1 backscatter data. Remote Sens. 2019, 11, 1569. [CrossRef]

62. Song, Y.; Wang, J. Mapping Winter Wheat Planting Area and Monitoring Its Phenology Using Sentinel-1 Backscatter Time Series. Remote Sens. 2019, 11, 449. [CrossRef]

63. Ashmitha, M.N.; Ahamed, M.J.; Pazhanivelan, S.; Kumaraperumal, R.; Ganesha Raj, K. Estimation of cotton and maize crop area in Perambalur district of Tamil Nadu using multi-date Sentinel-1A SAR data. Int. Arch. Photogramm. Remote Sens. Spat. Inf. Sci. ISPRS Arch. 2019, 42, 67-71. [CrossRef]

64. Vreugdenhil, M.; Wagner, W.; Bauer-Marschallinger, B.; Pfeil, I.; Teubner, I.; Rüdiger, C.; Strauss, P. Sensitivity of Sentinel-1 backscatter to vegetation dynamics: An Austrian case study. Remote Sens. 2018, 10, 1396. [CrossRef]

65. Topouzelis, K.; Singha, S. Incidence angle Normalization of Wide Swath SAR Data for Oceanographic Applications. Open Geosci. 2016, 8, 450-464. [CrossRef]

66. Mladenova, I.E.; Jackson, T.J.; Bindlish, R.; Hensley, S. Incidence Angle Normalization of Radar Backscatter Data. IEEE Trans. Geosci. Remote Sens. 2013, 51, 1791-1804. [CrossRef]

67. Revill, A.; Florence, A.; Macarthur, A.; Hoad, S.; Rees, R.; Williams, M. Quantifying uncertainty and bridging the scaling gap in the retrieval of leaf area index by coupling Sentinel-2 and UAV observations. Remote Sens. 2020, 12, 1843. [CrossRef]

68. Kljun, N.; Calanca, P.; Rotach, M.W.; Schmid, H.P. A simple two-dimensional parameterisation for Flux Footprint Prediction (FFP). Geosci. Model Dev. 2015, 8, 3695-3713. [CrossRef]

69. Corbari, C.; Ravazzani, G.; Galvagno, M.; Cremonese, E.; Mancini, M. Assessing crop coefficients for natural vegetated areas using satellite data and eddy covariance stations. Sensors 2017, 17, 2664. [CrossRef]

70. Rozenstein, O.; Haymann, N.; Kaplan, G.; Tanny, J. Validation of the cotton crop coefficient estimation model based on Sentinel-2 imagery and eddy covariance measurements. Agric. Water Manag. 2019, 223, 105715. [CrossRef]

71. Huang, C.; Zheng, X.; Tait, A.; Dai, Y.; Yang, C.; Chen, Z.; Li, T.; Wang, Z. On using smoothing spline and residual correction to fuse rain gauge observations and remote sensing data. J. Hydrol. 2014, 508, 410-417. [CrossRef]

72. Wright, J.; Lillesand, T.M.; Kiefer, R.W. Remote Sensing and Image Interpretation, 5th ed.; Flahive, R., Powell, D., Eds.; Wiley: Hoboken, NJ, USA, 2004; ISBN 0471026093.

73. Stateczny, A.; Kazimierski, W.; Kulpa, K. Radar and Sonar Imaging and Processing. Remote Sens. 2020, 12, 1811. [CrossRef]

74. Farr, T.G.; Rosen, P.A.; Caro, E.; Crippen, R.; Duren, R.; Hensley, S.; Kobrick, M.; Paller, M.; Rodriguez, E.; Roth, L.; et al. The Shuttle Radar Topography Mission. Rev. Geophys. 2007, 45, 44. [CrossRef]

75. Inoue, Y.; Sakaiya, E.; Wang, C. Potential of X-Band Images from High-Resolution Satellite SAR Sensors to Assess Growth and Yield in Paddy Rice. Remote Sens. 2014, 6, 5995-6019. [CrossRef]

76. Ndikumana, E.; Minh, D.H.T.; Nguyen, H.T.D.; Baghdadi, N.; Courault, D.; Hossard, L.; Moussawi, I. El Estimation of rice height and biomass using multitemporal SAR Sentinel-1 for Camargue, Southern France. Remote Sens. 2018, 10, 1394. [CrossRef]

77. Flores, A.; Herndon, K.; Thapa, R.; Cherrington, E. SAR Handbook: Comprehensive Methodologies for Forest Monitoring and Biomass Estimation, 1st ed.; SERVIR Global: Huntsville, AL, USA, 2019.

78. Kumar, D.; Rao, S.; Sharma, J.R. Radar Vegetation Index as an Alternative to NDVI for Monitoring of Soyabean and Cotton. In Proceedings of the XXXIII INCA International Congress, Jodhpur, India, 19-21 September 2013; pp. 91-96.

79. Trudel, M.; Charbonneau, F.; Leconte, R. Using RADARSAT-2 polarimetric and ENVISAT-ASAR dual-polarization data for estimating soil moisture over agricultural fields. Can. J. Remote Sens. 2012, 38, 514-527. [CrossRef]

80. Holtgrave, A.-K.; Röder, N.; Ackermann, A.; Erasmi, S.; Kleinschmit, B. Comparing Sentinel-1 and -2 Data and Indices for Agricultural Land Use Monitoring. Remote Sens. 2020, 12, 2919. [CrossRef] 
81. Richards, M. Fundamentals of Radar Signal Processing; McGraw-Hill: New York, NY, USA, 2005; ISBN 0-07-144474-2.

82. Mäkynen, M.P.; Manninen, A.T.; Similä, M.H.; Karvonen, J.A.; Hallikainen, M.T. Incidence angle dependence of the statistical properties of C-band $\mathrm{HH}$-polarization backscattering signatures of the Baltic Sea ice. IEEE Trans. Geosci. Remote Sens. 2002, 40, 2593-2605. [CrossRef]

83. Sabel, D.; Pathe, C.; Wagner, W.; Hasenauer, S.; Bartsch, A.; Künzer, C.; Scipal, K. Using ENVISAT ScanSAR data for characterising scaling properties of scatterometer derived soil moisture information over Southern Africa. In Proceedings of the ENVISAT Symposium, Montreux, Switzerland, 23-27 April 2007.

84. Lecomte, P.; Wagner, W. ERS Wind Scatterometer Commissioning and In-Flight Calibration. Available online: https:/ / earth.esa. int/documents/10174/1602497/WSC12.pdf (accessed on 25 June 2021).

85. Skolnik, M. Radar Handbook, 3rd ed.; McGraw-Hill: New York, NY, USA, 2008; ISBN 978-0-07-148547-0.

86. Rozenstein, O.; Siegal, Z.; Blumberg, D.G.; Adamowski, J. Investigating the backscatter contrast anomaly in synthetic aperture radar (SAR) imagery of the dunes along the Israel-Egypt border. Int. J. Appl. Earth Obs. Geoinf. 2016, 46, 13-21. [CrossRef]

87. Srivastava, H.S.; Patel, P.; Sharma, K.P.; Krishnamurthy, Y.V.N.; Dadhwal, V.K. A semi-empirical modelling approach to calculate two-way attenuation in radar backscatter from soil due to crop cover. Curr. Sci. 2011, 100, 1871-1874.

88. Ulaby, F. Radar response to vegetation. IEEE Trans. Antennas Propag. 1975, 23, 36-45. [CrossRef]

89. Da Silva, A.d.Q.; Paradella, W.R.; Freitas, C.C.; Oliveira, C.G. Evaluation of digital classification of polarimetric SAR data for iron-mineralized laterites mapping in the Amazon region. Remote Sens. 2013, 5, 3101-3122. [CrossRef]

90. Carver, K.R.; Elachi, C.; Ulaby, F.T. Microwave remote sensing from space. Proc. IEEE 1985, 73, 970-996. [CrossRef]

91. Richards, J.A. Remote Sensing with Imaging Radar; Signals and Communication Technology; Springer: Berlin/Heidelberg, Germany, 2009; ISBN 978-3-642-02019-3.

92. Moreira, A.; Prats-Iraola, P.; Younis, M.; Krieger, G.; Hajnsek, I.; Papathanassiou, K.P. A tutorial on synthetic aperture radar. IEEE Geosci. Remote Sens. Mag. 2013, 1, 6-43. [CrossRef]

93. Small, D.; Rohner, C.; Miranda, N.; Ruetschi, M.; Schaepman, M.E. Wide-Area Analysis-Ready Radar Backscatter Composites. IEEE Trans. Geosci. Remote Sens. 2021, 1-14. [CrossRef]

94. Frey, O.; Santoro, M.; Werner, C.L.; Wegmüller, U. DEM-based SAR pixel-area estimation for enhanced geocoding refinement and radiometric normalization. IEEE Geosci. Remote Sens. Lett. 2013, 10, 48-52. [CrossRef]

95. Raney, R.K.; Freeman, T.; Hawkins, R.W.; Bamler, R. A plea for radar brightness. In Proceedings of the Proceedings of IGARSS '94-1994 IEEE International Geoscience and Remote Sensing Symposium, Pasadena, CA, USA, 8-12 August 1994; Volume 2, pp. 1090-1092.

96. El-Darymli, K.; Mcguire, P. Understanding the Significance of Radiometric Calibration for Synthetic Aperture Radar Imagery. In Proceedings of the 2014 IEEE 27th Canadian Conference on Electrical and Computer Engineering (CCECE), Toronto, ON, Canada, 4-7 May 2014; 2014; pp. 1-6.

97. Kreslavsky, M. Venera-15,-16 radar brightness of Venus surface: Comparison with Magellan data. Abstr. Lunar Planet. Sci. Conf. $1995,26,799$.

98. Goldstein, R.M.; Melbourne, W.G.; Morris, G.A.; Downs, G.S.; Handley, D.A.O. Preliminary radar results of Mars. Radio Sci. 1970, 5, 475-478. [CrossRef]

99. Meyer, F.; Hinz, S. Automatic ship detection in space-borne SAR imagery. Int. Arch. Photogram. Remote Sens. Spat. Inform. Sci. 2009, 38, 1-6.

100. Maître, H. Processing of Synthetic Aperture Radar Images; Matre, H., Ed.; ISTE: London, UK, 2008; ISBN 9780470611111.

101. Steiger, J.H. Tests for comparing elements of a correlation matrix. Psychol. Bull. 1980, 87, 245-251. [CrossRef]

102. Fisher, R.A. On the Probable Error of a Coefficient of Correlation Deduced from a Small Sample. Metron 1921, 1, 3-32.

103. Wilcoxon, F. Individual Comparisons by Ranking Methods. Biometrics Bull. 1945, 1, 80-83. [CrossRef]

104. Button, K.S.; Ioannidis, J.P.A.; Mokrysz, C.; Nosek, B.A.; Flint, J.; Robinson, E.S.J.; Munafò, M.R. Power failure: Why small sample size undermines the reliability of neuroscience. Nat. Rev. Neurosci. 2013, 14, 365-376. [CrossRef]

105. Bréda, N.J.J. Ground-based measurements of leaf area index: A review of methods, instruments and current controversies. J. Exp. Bot. 2003, 54, 2403-2417. [CrossRef]

106. El-Shirbeny, M.A.; Abutaleb, K. Sentinel-1 Radar Data Assessment to Estimate Crop Water Stress. World J. Eng. Technol. 2017, 05, 47-55. [CrossRef]

107. Beeri, O.; Netzer, Y.; Munitz, S.; Mintz, D.F.; Pelta, R.; Shilo, T.; Horesh, A.; Mey-tal, S. Kc and LAI Estimations Using Optical and SAR Remote Sensing Imagery for Vineyards Plots. Remote Sens. 2020, 12, 3478. [CrossRef]

108. Cloude, S. Polarisation: Applications in Remote Sensing; Oxford University Press: Oxford, UK, 2010; ISBN 978-0-19-956973-1.

109. Verba, V.S.; Neronskiy, L.B.; Osipov, V.E.; Turuk, I.G. Spaceborne Earth Surveillance Radar Systems; Radiotechnika: Moscow, Russia, 2010.

110. Léonard, A.; Bériaux, E.; Defourny, P. Complementarity of Linear Polarizations in C-Band SAR Imagery to Estimate Leaf Area Index for Maize and Winter Wheat. Available online: https:/ / ftp.space.dtu.dk/pub/Ioana/papers/s444_1leon.pdf (accessed on 25 June 2021).

111. Naval Air Systems Command Electronic Warfare and Radar Systems Engineering Handbook, 2nd ed.; Naval Air Warfare Center: Point Mugu, CA, USA, 1999.

112. Skolnik, M. Introduction to Radar Systems, 2nd ed.; McGraw-Hili Book Co.: New York, NY, USA, 1981; ISBN 9786069276969. 
113. Zikidis, K. Early Warning Against Stealth Aircraft, Missiles and Unmanned Aerial Vehicles. In Surveillance in Action. Advanced Sciences and Technologies for Security Applications; Karampelas, P., Bourlai, T., Eds.; Springer International Publishing: Cham, Switzerland, 2018; ISBN 978-3-319-68532-8.

114. Shoshany, M.; Svoray, T.; Svoray, T.; Curran, P.J.; Foody, G.M.; Perevolotsky, A. The relationship between ERS-2 SAR backscatter and soil moisture: Generalization from a humid to semi-arid transect. Int. J. Remote Sens. 2000, 21, 2337-2343. [CrossRef]

115. Filgueiras, R.; Mantovani, E.C.; Althoff, D.; Fernandes Filho, E.I.; Cunha, F.F. da Crop NDVI Monitoring Based on Sentinel-1. Remote Sens. 2019, 11, 1441. [CrossRef]

116. Dinevich, L. Improving the accuracy of selection of bird radar echoes against a background of atomized clouds and atmospheric inhomogeneities. Ring 2016, 37, 3-18. [CrossRef]

117. NAWCWD Avionics Department. Electronic Warfare and Radar Systems. Engineering Handbook, 4th ed.; Naval Air Warfare Center: Point Mugu, CA, USA, 2013; ISBN 9781608077052.

118. Fenn, A.J. Adaptive Antennas and Phased Arrays for Radar and Communications; Artech House: Norwood, MA, USA, 2008; ISBN 9781596932739. 